\title{
Development of association rules to study the parametric influences in non-traditional machining processes
}

\author{
SUBHAM AGARWAL ${ }^{1}$, SHRUTI SUDHAKAR DANDGE ${ }^{2}$ and SHANKAR CHAKRABORTY ${ }^{1, *^{*}}$ \\ ${ }^{1}$ Department of Production Engineering, Jadavpur University, Kolkata, India \\ ${ }^{2}$ Mechanical Engineering Department, Government Polytechnic, Murtizapur, India \\ e-mail: s_chakraborty00@yahoo.co.in
}

MS received 7 May 2019; revised 21 August 2019; accepted 9 October 2019

\begin{abstract}
Non-traditional machining (NTM) processes have already emerged out as the suitable substitutes for the conventional metal removal methods due to their capability of generating complicated shape geometries on diverse difficult-to-machine engineering materials. For these NTM processes, it is always proposed that they should be operated while setting their various input parameters at the optimal levels for achieving better machining performance. In this paper, the application of a data mining tool in the form of development of association rules is explored to determine the best machining conditions for three NTM processes, i.e. electrochemical machining process, ultrasonic machining process and electrical discharge machining process. These rules, presented as simple 'If-Then' statements, would also guide the concerned process engineers in investigating the effects of various NTM process parameters on the considered responses. It is observed that the most preferred parametric combinations identified based on the generated association rules closely match with those as perceived by the past researchers.
\end{abstract}

Keywords. Non-traditional machining process; data mining; association rule; process parameter; response.

\section{Introduction}

In order to meet the ever increasing demands for higher production rate and dimensional accuracy, low surface roughness, generation of complex shape geometries on various advanced engineering materials with low machinability, etc., the conventional metal removal methods are being continuously substituted by the non-traditional machining (NTM) processes. These processes usually employ different energies, like mechanical, thermal, electrical or chemical energy or combination of them to remove tiny amounts of materials from the workpiece surfaces, even at atomic levels [1]. Unlike the conventional machining processes, in NTM processes, there may not be any contact between the tool and the work material, no restriction on the choice of the tool materials, no burr formation, no residual stress generation, no tool wear, etc. Due to their enhanced machining capabilities, they have now been extensively deployed to shape ultra-hard alloys in heavy industries and aerospace applications, machine ultrathin materials in electronic devices as microprocessors, generate complicated shape geometries in turbine blades, and fabricate blind or through holes in jet nozzles. They can even generate micro- and nano-features on diverse hard-tomachine materials with ease $[2,3]$. These NTM processes

*For correspondence

Published online: 01 November 2019 are often characterized by their various controllable (input) parameters and outputs (responses). Their material removal mechanisms are also very complex. Even the most experienced process engineers face the problems to clearly understand the relationships between different NTM process parameters and the corresponding responses. It may lead to variations in dimensional accuracy and surface roughness of the finally machined products/components.

With the increasing automation and rapid development of the computational intelligence, knowledge has received significant attention in manufacturing, especially in the domain of NTM processes, to build competitive advantages. Knowledge induction from data has now become extremely important in NTM processes so as to enhance productivity, understand the process mechanisms and improve the future process performance. It has now become the burden to the computers to quickly and exhaustively establish the relationships between various NTM process parameters and responses through the deployment of different data mining tools and techniques. Data mining is an evolving area of computational intelligence offering new iterative and interactive techniques for processing large volumes of data in order to explore valuable and understandable patterns hidden in the dataset. Availability of huge machining and manufacturing related data in digital form has also accelerated the application of data mining tools to aid the process engineers in identifying the 
tentative settings of various process parameters to obtain the desired response values. In data mining, development of association rules is one of the important areas of research, requiring more attention to be effectively augmented in the domain of NTM processes for their effective control. Association rules are simple 'If-Then' statements to help discover significant relationships between independent and dependant variables. In this paper, an attempt is put forward to develop the related association rules for three most widely used NTM processes, i.e. electrochemical machining (ECM), ultrasonic machining (USM) and electrical discharge machining (EDM) to identify their most favourable parametric settings so as to achieve the target response values. These rules would also assist the concerned process engineers in understanding the effects of the considered NTM process parameters on the outputs.

\section{Association rules}

The concept of data mining has been originated as one of the main developments of knowledge discovery in database (KDD). It has become an interdisciplinary field of study to develop techniques to extract or recognize consequential information or pattern from the given dataset. With the availability of huge volume of data and high speed computational facilities, the need of data mining techniques has been increased significantly in information related applications of manufacturing and managerial decision making. The application of data mining tools mainly includes machine learning, cluster analysis, regression analysis and neural networks. Based on a given training dataset, neural networks and regression analysis both create a single model using a predetermined set of features. On the other hand, a machine learning algorithm generates a number of models, usually in the form of decision rules, to highlight the predominant relationships between the input features and the decision. In cluster analysis, based on some specific features, similar objects are grouped into one cluster and dissimilar objects are segregated into another cluster. In machine learning algorithm, the set of features included in each rule can be independent from all other rules, similar to the result generated by cluster analysis. The developed models (rules) are explicit and are readily expressed in English to be easily understood by the decision makers. Sometimes, the contents of datasets with qualitative and categorical information are difficult to interpret unless the information is converted into simple rules. The rule extraction algorithms in data mining are designed to identify patterns in such datasets, while articulating them as decision rules [4-6].

Involving the use of machine learning tools, the association rules, as the name proposes, are straightforward 'IfThen' statements to analyze frequently occurring patterns in a dataset or discover inherent relationships between independent and dependant variables in a dataset. These rules are suitable for non-numeric, categorical data, developed just by simple counting. An association rule has two components, i.e. an antecedent (if) and a consequent (then) [7, 8]. An antecedent is an item found within the dataset, whereas, a consequent is an item observed in combination with the antecedent. The 'If-Then' expression thus attains a form, like 'If condition Then conclusion'. These rules are generated while searching the dataset for the occurrence of frequent 'If-Then' patterns, and the most important relationships are later validated by the support and confidence criteria. Support indicates how frequently the items appear in the dataset, whereas, confidence is the measure of the number of times the 'If-Then' statements are found true [9]. The earlier researchers have already developed the related association rules for manufacturing process control [10], defect identification in printed-circuit boards [11], semiconductor manufacturing [12], manufacturing defect detection [13], product design and manufacturing process improvement [14], automotive warranty data [15], supplier selection [16], product and process variety mapping [17], foundry process [18], carpet manufacturing [19], product quality improvement [20], total productive maintenance [21], material selection [22], etc.

Now, in order to demonstrate generation of association rules in any of the NTM processes, the simple dataset of table 1 is considered here. In this process with five experimental runs, there are three input parameters $\left(a_{1}, a_{2}\right.$ and $a_{3}$ ), each with three different operating levels (1, 2 and 3 ). On the other hand, there are four outputs (responses) $\left(a_{4}, a_{5}\right.$, $\mathrm{a}_{6}$ and $\mathrm{a}_{7}$ ), each having three varying levels (low, medium and high). Thus, the first row of table 1 signifies that when all the three input parameters are set at ' 1 ' level, 'Low' values for the four responses are simultaneously observed. It has often been observed that a given dataset may contain duplicate parameters and responses which make it bulky and difficult to interpret. Thus, it becomes compulsory to minimize the numbers of parameters and responses in the original dataset for efficient framing of the association rules. The dataset can be reduced while estimating the values of dependency index between pairs of parameters and responses. The parameters or responses with higher dependency indexes with respect to a predefined threshold value are usually removed from the original dataset,

Table 1. Illustrative machining dataset.

\begin{tabular}{|c|c|c|c|c|c|c|c|}
\hline \multirow[b]{2}{*}{ Exp. run } & \multicolumn{3}{|c|}{ Input parameter } & \multicolumn{4}{|c|}{ Response } \\
\hline & $a_{1}$ & $a_{2}$ & $\mathrm{a}_{3}$ & $\mathrm{a}_{4}$ & $a_{5}$ & $a_{6}$ & $a_{7}$ \\
\hline 1 & 1 & 1 & 1 & Low & Low & Low & Low \\
\hline 2 & 1 & 2 & 2 & Low & Low & Low & Low \\
\hline 3 & 2 & 1 & 1 & Medium & Medium & High & Medium \\
\hline 4 & 3 & 1 & 2 & Medium & High & Medium & Medium \\
\hline 5 & 3 & 3 & 3 & High & Medium & Medium & High \\
\hline
\end{tabular}


without losing much information. The dependency index can be computed as follows [10]:

$$
\begin{gathered}
\mathrm{K}\left(\mathrm{a}_{i}, \mathrm{a}_{j}\right)=\sum_{\mathrm{L} \in \mathrm{a}_{j}^{*}} \frac{\mid \underline{\mathrm{a}_{i}(\mathrm{~L}) \mid}}{\mathrm{N}} \\
\underline{\mathrm{a}_{i}}(\mathrm{~L})=\cup\left\{\mathrm{Y} \in \mathrm{a}_{i}^{*} \mid \mathrm{Y} \subseteq \mathrm{L}\right\}
\end{gathered}
$$

where $a_{i}^{*}$ and $a_{j}^{*}$ are the equivalence classes of attributes $a_{i}$ and $a_{j}$ respectively (the equivalence class is the set of objects with the same value for attributes $a_{i}$ and $a_{j}$ ), $L$ is the equivalence class of $\mathrm{a}_{j}, \mathrm{Y}$ is the equivalence class of $\mathrm{a}_{i}, \mathrm{~N}$ is the total number of objects in the dataset, $|\bullet|$ is the cardinality of a set (number of elements in the set) and $\underline{a}_{i}(\mathrm{~L})$ is the lower approximation of set $\mathrm{L}$ over attribute $\mathrm{a}_{i}$.

While reducing the dataset, a dependency index of $\mathrm{K}\left(\mathrm{a}_{i}, \mathrm{a}_{j}\right)=0$ denotes the independency between two parameters (attributes) $\mathrm{a}_{i}$ and $\mathrm{a}_{j}$, whereas, $\mathrm{K}\left(a_{i}, a_{j}\right)=100$ signifies their entire dependency. For a given threshold value (which is usually assumed as $85-90 \%$ ), it is required to determine both the dependency indexes, i.e. $\mathrm{K}\left(\mathrm{a}_{i}, \mathrm{a}_{j}\right)$ and $\mathrm{K}\left(\mathrm{a}_{j}, \mathrm{a}_{i}\right)$. Elimination of one of the attributes can only be possible if $\min \left\{\mathrm{K}\left(\mathrm{a}_{i}, \mathrm{a}_{j}\right), \mathrm{K}\left(\mathrm{a}_{j}, \mathrm{a}_{i}\right)\right\}$ is greater than the threshold value. When the threshold value is high, more number of incompetent attributes remains in the dataset, making generation of the association rules more complicated. Similarly, its lower value causes many useful attributes getting eliminated from the original dataset with loss of valuable information. Thus, setting of the appropriate threshold value plays a major role in development of the subsequent association rules. Now, using Eqs. (1)-(2), the related matrix showing the values of dependency index for the considered machining attributes is developed, as provided in table 2 . In this table, as $\mathrm{K}\left(\mathrm{a}_{4}, \mathrm{a}_{7}\right)=\mathrm{K}\left(\mathrm{a}_{7}, \mathrm{a}_{4}\right)=100$, there are strong dependencies between these two responses $\left(a_{4}\right.$ and $\left.a_{7}\right)$, and any of them can be eliminated from the initial dataset for a threshold value of $90 \%$. Here, response $\mathrm{a}_{7}$ is discarded from further consideration and the reduced dataset is shown in table 3. It can be observed from table 2 that the values of the dependency index for $\mathrm{K}\left(\mathrm{a}_{1}, \mathrm{a}_{6}\right)$ and $\mathrm{K}\left(\mathrm{a}_{6}, \mathrm{a}_{1}\right)$ are also $100 \%$. However, neither of them can be eliminated because they belong to different attribute classes, i.e. $\mathrm{a}_{1}$ is an input parameter and $\mathrm{a}_{6}$ is a response.

Table 2. Dependency indexes between the attributes.

\begin{tabular}{llllllll}
\hline Attribute & $\mathrm{a}_{1}$ & $\mathrm{a}_{2}$ & $\mathrm{a}_{3}$ & $\mathrm{a}_{4}$ & $\mathrm{a}_{5}$ & $\mathrm{a}_{6}$ & $\mathrm{a}_{7}$ \\
\hline $\mathrm{a}_{1}$ & - & 40 & 20 & 60 & 60 & 100 & 60 \\
$\mathrm{a}_{2}$ & 20 & - & 60 & 60 & 20 & 20 & 60 \\
$\mathrm{a}_{3}$ & 20 & 40 & - & 20 & 20 & 20 & 20 \\
$\mathrm{a}_{4}$ & 60 & 40 & 20 & - & 60 & 60 & 100 \\
$\mathrm{a}_{5}$ & 60 & 40 & 20 & 60 & - & 60 & 60 \\
$\mathrm{a}_{6}$ & 100 & 40 & 20 & 60 & 60 & - & 60 \\
$\mathrm{a}_{7}$ & 60 & 40 & 20 & 100 & 60 & 60 & - \\
\hline
\end{tabular}

Table 3. Reduced dataset.

\begin{tabular}{ccccccc}
\hline Exp. run & $\mathrm{a}_{1}$ & $\mathrm{a}_{2}$ & $\mathrm{a}_{3}$ & \multicolumn{1}{c}{$\mathrm{a}_{4}$} & \multicolumn{1}{c}{$\mathrm{a}_{5}$} & \multicolumn{1}{c}{$\mathrm{a}_{6}$} \\
\hline 1 & 1 & 1 & 1 & Low & Low & Low \\
2 & 1 & 2 & 2 & Low & Low & Low \\
3 & 2 & 1 & 1 & Medium & Medium & High \\
4 & 3 & 1 & 2 & Medium & High & Medium \\
5 & 3 & 3 & 3 & High & Medium & Medium \\
\hline
\end{tabular}

Based on the reduced dataset and $k$-means algorithm, the considered attributes sometimes need to be organized themselves into different clusters for effective generation of the corresponding association rules. Now, an association rule generation algorithm is adopted to form 'If-Then' rules from the reduced dataset with the attributes classified into appropriate number of clusters. This rule generation algorithm is presented as below [10]:

Step 1: Initialize: $\mathrm{D}=\left\{\mathrm{d}_{1}, \mathrm{~d}_{2}, \ldots, \mathrm{d}_{n}\right\} ; \mathrm{R}=\left\{\mathrm{r}_{1}, \mathrm{r}_{2}, \ldots, \mathrm{r}_{m}\right\}$

Step 2: Evaluate $\mathrm{X}_{i j}=\mathrm{D}_{i} \cap \mathrm{R}_{j}$ for $i=1,2, \ldots, p ; j=$ $1,2, \ldots, q$

Step 3: For each $X_{i j} \neq \varnothing$, a rule is generated as follows:

If $\mathrm{d}_{1}=\mathrm{V}\left(\mathrm{D}_{i}, \mathrm{~d}_{1}\right)$ and $\ldots$ and $\mathrm{d}_{n}=\mathrm{V}\left(\mathrm{D}_{i}, \mathrm{~d}_{n}\right)$ Then $\mathrm{r}_{1}=\mathrm{V}\left(\mathrm{R}_{j}, \mathrm{r}_{1}\right)$ and... and $\mathrm{r}_{m}=\mathrm{V}\left(\mathrm{R}_{j}, \mathrm{r}_{m}\right)$

$[\mathrm{P}, \mathrm{Q}, \mathrm{C}, \mathrm{QTY}][\mathrm{T}]$

where $\quad \mathrm{P}=\frac{\left|\mathrm{X}_{i j}\right|}{\left|\mathrm{D}_{i}\right|} ; \quad \mathrm{Q}=\frac{\left|\mathrm{X}_{i i}\right|}{\left|\mathrm{R}_{j}\right|} ; \mathrm{C}=\frac{\left|\mathrm{X}_{i j}\right|}{\mathrm{N}} ; \quad \mathrm{QTY}=\left|\mathrm{X}_{i j}\right|$; $\mathrm{T}=\mathrm{P}+\mathrm{Q}+\mathrm{C}$

where $\mathrm{D}=\left\{\mathrm{d}_{1}, \mathrm{~d}_{2}, \ldots, \mathrm{d}_{n}\right\}$ is the set of condition attributes, $\mathrm{R}$ $=\left\{\mathrm{r}_{1}, \mathrm{r}_{2}, \ldots, \mathrm{r}_{m}\right\}$ is the set of decision attributes, $\mathrm{D}_{i}$ is $i^{\text {th }}$ equivalence classes of $\mathrm{D}(i=1,2, \ldots, p), \mathrm{R}_{j}$ is $j^{\text {th }}$ equivalence class of $\mathrm{R}(j=1,2, \ldots, q), \mathrm{V}\left(\mathrm{D}_{i}, \mathrm{~d}_{\mathrm{k}}\right)$ are the values of condition attributes in equivalence classes of $\mathrm{D}_{i}, \mathrm{~V}\left(\mathrm{R}_{i}, \mathrm{r}_{l}\right)$ are the values of decision attributes in equivalence classes of $\mathbf{R}_{j}$, $\mathrm{X}_{i j}$ is the intersection of $\mathrm{D}_{i}$ and $\mathrm{R}_{j}, \mathrm{P}$ is the percentage of objects in a current equivalence class of condition attribute set that correspond to a rule (a measure of rule confidence), $\mathrm{Q}$ is the percentage of objects in current equivalence class of decision attribute set that correspond to a rule, $\mathrm{C}$ is the percentage of objects that correspond to a rule (a measure of rule support) and QTY is the number of objects corresponding to a rule. In this algorithm, $\mathrm{T}$ represents the total strength (relative importance) of a rule. Higher value of $T$ signifies more strength of a particular association rule for effective decision making. To demonstrate the rule generation algorithm, using the reduced dataset of table 3 , sets $\mathrm{D}$ $=\left\{a_{1}\right\}$ and $R=\left\{a_{4}\right\}$ are first initialized. The equivalence classes are now evaluated.

$D_{1}=\{1,2\}, D_{2}=\{3\}, D_{3}=\{4,5\}, R_{1}=\{1,2\}, R_{2}=\{3,4\}$, $\mathrm{R}_{3}=\{5\}$

$\mathrm{V}\left(\mathrm{D}_{1}, \mathrm{~d}_{1}\right)=1, \mathrm{~V}\left(\mathrm{D}_{2}, \mathrm{~d}_{2}\right)=2, \mathrm{~V}\left(\mathrm{D}_{3}, \mathrm{~d}_{3}\right)=3, \mathrm{~V}\left(\mathrm{R}_{1}, \mathrm{r}_{1}\right)=$ Low, $\mathrm{V}\left(\mathrm{R}_{2}, \mathrm{r}_{2}\right)=$ Medium, $\mathrm{V}\left(\mathrm{R}_{3}, \mathrm{r}_{3}\right)=$ High 
In step 2, the intersections are determined.

$\mathrm{X}_{11}=\mathrm{D}_{1} \cap \mathrm{R}_{1}=\{1,2\}, \mathrm{X}_{12}=\mathrm{D}_{1} \cap \mathrm{R}_{2}=\varnothing, \mathrm{X}_{13}=\mathrm{D}_{1} \cap \mathrm{R}_{3}=\varnothing$,

$X_{21}=D_{2} \cap R_{1}=\varnothing, X_{22}=D_{2} \cap R_{2}=\{3\}, X_{23}=D_{2} \cap R_{3}=\varnothing$,

$X_{31}=D_{3} \cap R_{1}=\varnothing, X_{32}=D_{3} \cap R_{2}=\{4\}, X_{33}=D_{3} \cap R_{3}=\{5\}$.

In step 3, 'If-Then' rules showing the relationships between $\mathrm{a}_{1}$ as the input parameter and $\mathrm{a}_{4}$ as the response are generated.

Rule 1: If $\mathrm{a}_{1}=1$ Then $\mathrm{a}_{4}$ is Low $[\mathrm{P}=100, \mathrm{Q}=100, \mathrm{C}=40$, $\mathrm{QTY}=2][\mathrm{T}=240]$

Rule 2: If $\mathrm{a}_{1}=2$ Then $\mathrm{a}_{4}$ is Medium $[\mathrm{P}=100, \mathrm{Q}=100, \mathrm{C}=$ $20, \mathrm{QTY}=1][\mathrm{T}=220]$

Rule 3: If $\mathrm{a}_{1}=3$ Then $\mathrm{a}_{4}$ is Medium $[\mathrm{P}=100, \mathrm{Q}=100, \mathrm{C}=$ 20, QTY = 1][T = 220]

Rule 4: If $\mathrm{a}_{1}=3$ Then $\mathrm{a}_{4}$ is High $[\mathrm{P}=100, \mathrm{Q}=100, \mathrm{C}=20$, $\mathrm{QTY}=1][\mathrm{T}=220]$

In the above-developed rules, rules 3 and 4 would confuse the decision makers because at the input parameter setting of $\mathrm{a}_{1}=3$, the response $\left(\mathrm{a}_{4}\right)$ is both 'Medium' and 'High' which is almost impossible to occur. To avoid this problem, it is always advised to generate association rules while taking into account the input parameters altogether. Now, the following rules are developed for the considered responses incorporating all the input parameters.

For $\mathrm{a}_{4}$ :

Rule 1: If $\mathrm{a}_{1}=1$ Then $\mathrm{a}_{4}$ is Low $[\mathrm{P}=100, \mathrm{Q}=100, \mathrm{C}=40$, QTY = 2][T = 240]

Rule 2: If $\mathrm{a}_{2}=1$ Then $\mathrm{a}_{4}$ is Medium $[\mathrm{P}=66.66, \mathrm{Q}=100, \mathrm{C}$ $=40, \mathrm{QTY}=2][\mathrm{T}=206.66]$

Rule 3: If $\mathrm{a}_{1}=3$ and $\mathrm{a}_{2}=3$ and $\mathrm{a}_{3}=3$ Then $\mathrm{a}_{4}$ is High $[\mathrm{P}=$ $100, \mathrm{Q}=100, \mathrm{C}=20, \mathrm{QTY}=1][\mathrm{T}=220]$

For $\mathrm{a}_{5}$ :

Rule 1: If $\mathrm{a}_{1}=1$ Then $\mathrm{a}_{5}$ is Low $[\mathrm{P}=100, \mathrm{Q}=100, \mathrm{C}=40$, $\mathrm{QTY}=2][\mathrm{T}=240]$

Rule 2: If $\mathrm{a}_{1}=2$ and $\mathrm{a}_{2}=1$ and $\mathrm{a}_{3}=1$ Then $\mathrm{a}_{5}$ is Medium [P $=100, \mathrm{Q}=50, \mathrm{C}=20, \mathrm{QTY}=1][\mathrm{T}=170]$

Rule 3: If $\mathrm{a}_{1}=3$ and $\mathrm{a}_{2}=3$ and $\mathrm{a}_{3}=3$ Then $\mathrm{a}_{5}$ is Medium [P $=100, \mathrm{Q}=50, \mathrm{C}=20, \mathrm{QTY}=1][\mathrm{T}=170]$

Rule 4: If $\mathrm{a}_{1}=3$ and $\mathrm{a}_{2}=1$ and $\mathrm{a}_{3}=2$ Then $\mathrm{a}_{5}$ is High $[\mathrm{P}=$ $100, \mathrm{Q}=100, \mathrm{C}=20, \mathrm{QTY}=1][\mathrm{T}=220]$

For $\mathrm{a}_{6}$ :

Rule 1: If $\mathrm{a}_{1}=1$ Then $\mathrm{a}_{6}$ is Low $[\mathrm{P}=100, \mathrm{Q}=100, \mathrm{C}=40$, $\mathrm{QTY}=2]$ [T = 240]

Rule 2: If $\mathrm{a}_{1}=3$ Then $\mathrm{a}_{6}$ is Medium $[\mathrm{P}=100, \mathrm{Q}=100, \mathrm{C}=$ 40, QTY = 2] [T = 240]

Rule 3: If $\mathrm{a}_{1}=2$ and $\mathrm{a}_{2}=1$ and $\mathrm{a}_{3}=1$ Then $\mathrm{a}_{6}$ is High $[\mathrm{P}=$ $100, \mathrm{Q}=100, \mathrm{C}=20, \mathrm{QTY}=1][\mathrm{T}=220]$

For all the responses:

Rule 1: If $a_{1}=1$ Then $a_{4}$ is Low and $a_{5}$ is Low and $a_{6}$ is Low [P =100, Q=100, C=40, QTY=2] [T=240]

Rule 2: If $\mathrm{a}_{1}=2$ and $\mathrm{a}_{2}=1$ and $\mathrm{a}_{3}=1$ Then $\mathrm{a}_{4}$ is Medium and $\mathrm{a}_{5}$ is Medium and $\mathrm{a}_{6}$ is High $[\mathrm{P}=100, \mathrm{Q}=100, \mathrm{C}=20$, QTY=1] [T=220]

Rule 3: If $\mathrm{a}_{1}=3$ and $\mathrm{a}_{2}=1$ and $\mathrm{a}_{3}=2$ Then $\mathrm{a}_{4}$ is Medium and $\mathrm{a}_{5}$ is High and $\mathrm{a}_{6}$ is Medium $[\mathrm{P}=100, \mathrm{Q}=100, \mathrm{C}=20$, $\mathrm{QTY}=1][\mathrm{T}=220]$
Rule 4: If $\mathrm{a}_{1}=3$ and $\mathrm{a}_{2}=3$ and $\mathrm{a}_{3}=3$ Then $\mathrm{a}_{4}$ is High and $\mathrm{a}_{5}$ is Medium and $\mathrm{a}_{6}$ is Medium $[\mathrm{P}=100, \mathrm{Q}=100, \mathrm{C}=20$, QTY=1] [T=220]

The rules developed incorporating all the responses are supposed to be more useful for simultaneous optimization of a particular process. Thus, it can be observed that at setting $\mathrm{a}_{1}=1$, 'Low' values of all the responses are concurrently achieved, with a maximum rule strength of 240 .

\section{Illustrative examples}

It has already been mentioned that for having enhanced machining performance of NTM processes, investigation of the influences of various input parameters on the responses and determination of the optimal combinations of the considered process parameters are very important. To fulfil this objective, in this paper, a data mining tool in the form of generation of association rules is applied to analyze the experimental data of three different NTM processes, i.e. ECM, USM and EDM. The developed rules would assist the process engineers in achieving the desired values of various responses.

\subsection{ECM process}

In ECM process, material is removed from the workpiece by anodic dissolution of electrolyte based on Faraday's law of electrolysis. It involves two electrodes, connected to high voltage power supply, and a very small gap is maintained between them separated by electrolyte for efficient exchange of ions, causing material removal. Using an METATECH ECM setup and based on Taguchi's orthogonal array design plan, Rao and Padmanabhan [23] performed 27 experiments on $\mathrm{LM} 6 \mathrm{Al} / \mathrm{B}_{4} \mathrm{C}$ composite materials while considering voltage, feed rate, electrolyte concentration and percentage of reinforcement of boron carbide particles in the considered alloy matrix as the input parameters. Each of these parameters was set at three different levels, as shown in table 4 . In this process, material removal rate (MRR) (in g/min), surface roughness (SR) (in $\mu \mathrm{m}$ ) and radial overcut (ROC) (in $\mathrm{mm}$ ) were the responses. Among them, MRR is the only 'larger-the-better' (LTB) type of quality characteristic, whereas, SR and ROC are 'smaller-the-better' (STB) type of characteristics. The detailed experimental plan and measured response values are provided in table 5 .

Before generating the corresponding association rules for studying the performance of the ECM process, it is essential to preprocess the initial experimental dataset with an attempt to eliminate redundant information. In table 6 , the dependency indexes are estimated for each pair of the attributes. Lower values of these indexes than the threshold limit of $90 \%$ validate entire independency between 
Table 4. ECM process parameters and their levels [23].

\begin{tabular}{|c|c|c|c|c|c|}
\hline \multirow[b]{2}{*}{ Parameter } & \multirow[b]{2}{*}{ Symbol } & \multirow[b]{2}{*}{ Unit } & \multicolumn{3}{|c|}{ Level } \\
\hline & & & 1 & 2 & 3 \\
\hline Voltage & VL & $\mathrm{V}$ & 12 & 16 & 20 \\
\hline Feed rate & FR & $\mathrm{mm} / \mathrm{min}$ & 0.2 & 0.6 & 1.0 \\
\hline Electrolyte concentration & $\mathrm{EC}$ & $\mathrm{g} / \mathrm{l}$ & 10 & 20 & 30 \\
\hline Percentage of reinforcement & POR & $\mathrm{Wt} \%$ & 2.5 & 5.0 & 7.5 \\
\hline
\end{tabular}

Table 5. Experimental plan and responses for the ECM process [23].

\begin{tabular}{cccccccl}
\hline Exp. no. & VL & FR & EC & POR & MRR & SR & ROC \\
\hline 1 & 1 & 1 & 1 & 1 & 0.268 & 4.948 & 0.96 \\
2 & 1 & 1 & 2 & 2 & 0.335 & 5.002 & 0.94 \\
3 & 1 & 1 & 3 & 3 & 0.227 & 4.591 & 0.79 \\
4 & 1 & 2 & 1 & 1 & 0.353 & 4.92 & 0.75 \\
5 & 1 & 2 & 2 & 2 & 0.448 & 4.498 & 0.65 \\
6 & 1 & 2 & 3 & 3 & 0.42 & 4.725 & 0.8 \\
7 & 1 & 3 & 1 & 1 & 0.689 & 4.555 & 0.67 \\
8 & 1 & 3 & 2 & 2 & 0.545 & 4.356 & 0.64 \\
9 & 1 & 3 & 3 & 3 & 0.703 & 4.232 & 0.65 \\
10 & 2 & 1 & 1 & 2 & 0.321 & 4.882 & 0.91 \\
11 & 2 & 1 & 2 & 3 & 0.329 & 4.823 & 0.94 \\
12 & 2 & 1 & 3 & 1 & 0.488 & 4.254 & 1.05 \\
13 & 2 & 2 & 1 & 2 & 0.379 & 4.54 & 0.76 \\
14 & 2 & 2 & 2 & 3 & 0.302 & 4.431 & 0.69 \\
15 & 2 & 2 & 3 & 1 & 0.583 & 3.998 & 0.99 \\
16 & 2 & 3 & 1 & 2 & 0.615 & 4.274 & 0.75 \\
17 & 2 & 3 & 2 & 3 & 0.619 & 4.346 & 0.7 \\
18 & 2 & 3 & 3 & 1 & 0.812 & 3.598 & 0.93 \\
19 & 3 & 1 & 1 & 3 & 0.282 & 5.472 & 0.91 \\
20 & 3 & 1 & 2 & 1 & 0.599 & 4.797 & 1.1 \\
21 & 3 & 1 & 3 & 2 & 0.603 & 4.64 & 1.16 \\
22 & 3 & 2 & 1 & 3 & 0.526 & 5.214 & 0.85 \\
23 & 3 & 2 & 2 & 1 & 0.688 & 4.897 & 1.03 \\
24 & 3 & 2 & 3 & 2 & 0.732 & 4.531 & 1.08 \\
25 & 3 & 3 & 1 & 3 & 0.688 & 5.002 & 0.64 \\
26 & 3 & 3 & 2 & 1 & 0.887 & 4.389 & 0.99 \\
27 & 3 & 3 & 3 & 2 & 0.944 & 3.989 & 1 \\
\hline & & & & & & &
\end{tabular}

different attributes. Now, using $k$-means algorithm, the responses in table 5 are grouped into suitable number of clusters to transform their continuous values into separate distinguishable ranges. In figure 1, each of the three ECM responses is grouped into two separate clusters, designated as 'Low' and 'High'. For MRR, 'High' values are always preferred, whereas, 'Low' values are desired for the remaining responses. The details of the cluster analysis results for the ECM process are provided in table 7 . The mean and range for each cluster for the three responses are shown in columns 3 and 4 respectively. Column 5 highlights the specific objects (experimental runs) and column 6
Table 6. Dependency indexes for different ECM attributes.

\begin{tabular}{llllllll}
\hline Attribute & VL & FR & EC & POR & MRR & SR & ROC \\
\hline VL & - & 0 & 0 & 0 & 0 & 0 & 0 \\
FR & 0 & - & 0 & 0 & 0 & 0 & 0 \\
EC & 0 & 0 & - & 0 & 0 & 0 & 0 \\
POR & 0 & 0 & 0 & - & 0 & 0 & 0 \\
MRR & 0 & 33.33 & 0 & 0 & - & 0 & 0 \\
SR & 0 & 0 & 0 & 0 & 0 & - & 0 \\
ROC & 0 & 0 & 0 & 0 & 0 & 0 & - \\
\hline
\end{tabular}

shows the total number of objects in each cluster. Now, based on the experimental dataset of table 5, the resultant association rules depicting the relationships between various ECM process parameters and responses are generated using ROSE2 (version 2.2) rough sets data explorer. In the first three sets of rules, one or more ECM process parameters are assigned to a single response, while, in the last set, rules accommodating all the three responses are generated.

\section{For MRR:}

Rule 1: If $\mathrm{VL}=12 \mathrm{~V}$ and $\mathrm{FR}=0.2 \mathrm{~mm} / \mathrm{min}$ Then MRR is $0.346 \mathrm{~g} / \mathrm{min}[0.227-0.490][\mathrm{P}=100 \%, \mathrm{Q}=25 \%, \mathrm{C}=$ $11.11 \%, \mathrm{QTY}=3]$ [T $=136.11]$

Rule 2: If $\mathrm{VL}=16 \mathrm{~V}$ and $\mathrm{FR}=0.2 \mathrm{~mm} / \mathrm{min}$ Then MRR is $0.346 \mathrm{~g} / \mathrm{min}[0.227-0.490][\mathrm{P}=100 \%, \mathrm{Q}=25 \%, \mathrm{C}=$ $11.11 \%, \mathrm{QTY}=3]$ [T = 136.11]

Rule 3: If $\mathrm{VL}=12 \mathrm{~V}$ and $\mathrm{FR}=0.6 \mathrm{~mm} / \mathrm{min}$ Then MRR is $0.346 \mathrm{~g} / \mathrm{min}[0.227-0.490][\mathrm{P}=100 \%, \mathrm{Q}=25 \%, \mathrm{C}=$ $11.11 \%, \mathrm{QTY}=3]$ [T = 136.11]

Rule 4: If $\mathrm{VL}=16 \mathrm{~V}$ and $\mathrm{FR}=0.6 \mathrm{~mm} / \mathrm{min}$ and $\mathrm{EC}=10$ $\mathrm{g} / 1$ Then MRR is $0.346 \mathrm{~g} / \mathrm{min}[0.227-0.490]$ [P $=100 \%, \mathrm{Q}$ $=8.33 \%, \mathrm{C}=3.70 \%, \mathrm{QTY}=1][\mathrm{T}=112.03]$

Rule 5: If $\mathrm{VL}=16 \mathrm{~V}$ and $\mathrm{FR}=0.6 \mathrm{~mm} / \mathrm{min}$ and $\mathrm{POR}=7.5$ $\mathrm{Wt} \%$ Then MRR is $0.346 \mathrm{~g} / \mathrm{min}[0.227-0.490]$ [P $=100 \%$, $\mathrm{Q}=8.33 \%, \mathrm{C}=3.70 \%, \mathrm{QTY}=1][\mathrm{T}=112.03]$

Rule 6: If FR $=0.2 \mathrm{~mm} / \mathrm{min}$ and $\mathrm{EC}=10 \mathrm{~g} / \mathrm{l}$ Then MRR is $0.346 \mathrm{~g} / \mathrm{min}[0.227-0.490][\mathrm{P}=100 \%, \mathrm{Q}=25 \%, \mathrm{C}=$ $11.11 \%, \mathrm{QTY}=3][\mathrm{T}=136.11]$

Rule 7: If FR $=1.0 \mathrm{~mm} / \mathrm{min}$ Then MRR is $0.682 \mathrm{~g} / \mathrm{min}$ [0.490-0.944] $[\mathrm{P}=100 \%, \mathrm{Q}=60 \%, \mathrm{C}=33.33 \%$, QTY $=$ 9] $[\mathrm{T}=193.33]$ 

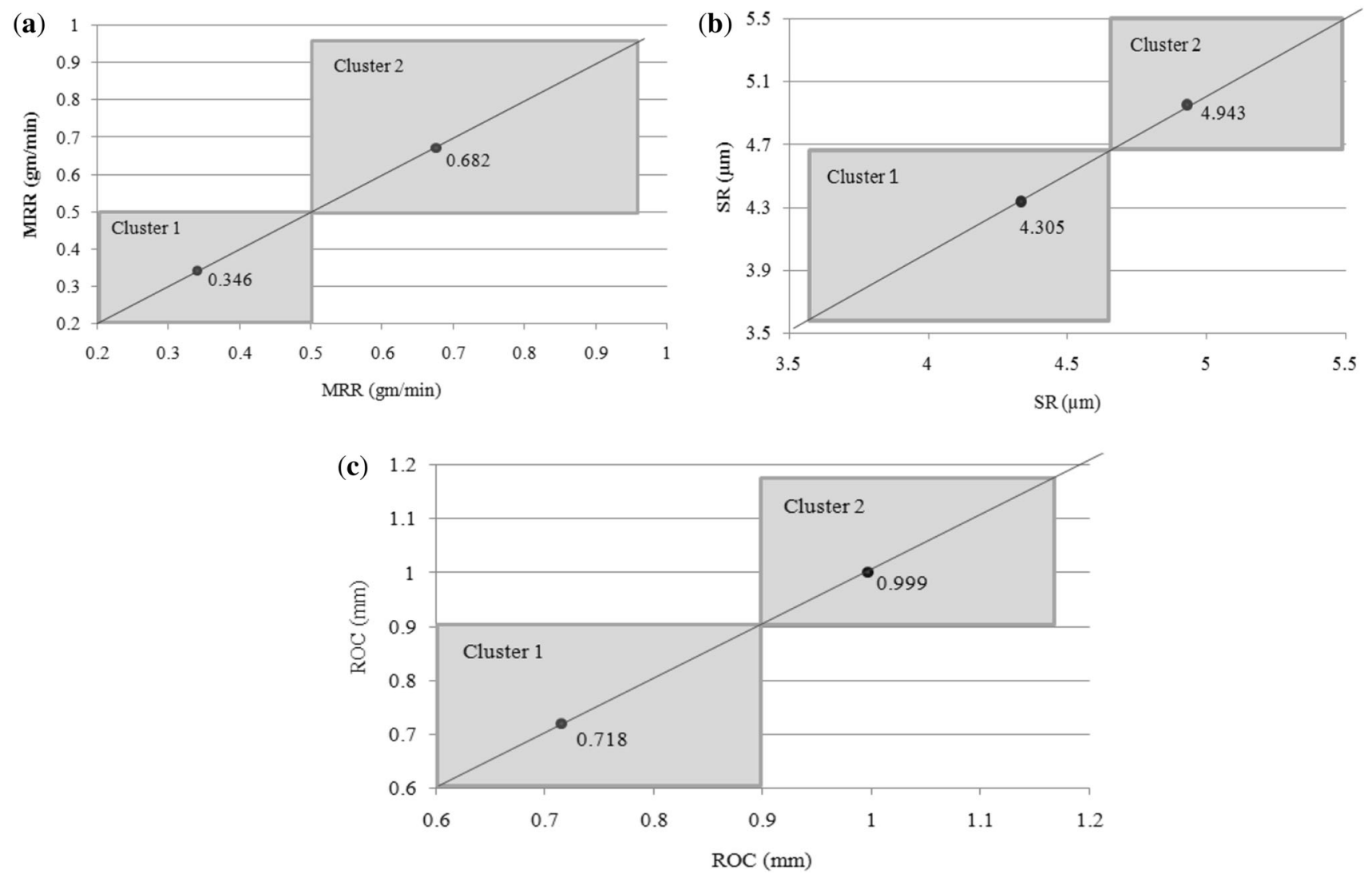

Figure 1. Clustering of the ECM responses.

Table 7. Details of the formed clusters for the ECM process.

\begin{tabular}{lrcccc}
\hline \multirow{2}{*}{ Response } & $\begin{array}{c}\text { Cluster } \\
\text { number }\end{array}$ & Mean & Range of each cluster & \multicolumn{1}{c}{ Objects } & Number of objects in each cluster \\
\hline MRR & Cluster 1 & 0.346 & $0.227-0.490$ & $1,2,3,4,5,6,10,11,12,13,14,19$ & 12 \\
& Cluster 2 & 0.682 & $0.490-0.944$ & $7,8,9,15,16,17,18,20,21,22,23,24,25,26,27$ & 15 \\
SR & Cluster 1 & 4.305 & $3.598-4.600$ & $3,5,7,8,9,12,13,14,15,16,17,18,24,26,27$ & 15 \\
& Cluster 2 & 4.943 & $4.600-5.472$ & $1,2,4,6,10,11,19,20,21,22,23,25$ & 12 \\
ROC & Cluster 1 & 0.718 & $0.640-0.900$ & $3,4,5,6,7,8,9,13,14,16,17,22,25$ & 13 \\
& Cluster 2 & 0.999 & $0.900-1.160$ & $1,2,10,11,12,15,18,19,20,21,23,24,26,27$ & 14 \\
\hline
\end{tabular}

Rule 8: If $\mathrm{VL}=20 \mathrm{~V}$ and $\mathrm{FR}=0.6 \mathrm{~mm} / \mathrm{min}$ Then $\mathrm{MRR}$ is $0.682 \mathrm{~g} / \mathrm{min}[0.490-0.944][\mathrm{P}=100 \%, \mathrm{Q}=20 \%, \mathrm{C}=$ $11.11 \%$, QTY $=3][\mathrm{T}=131.11]$

Rule 9: If $\mathrm{VL}=20 \mathrm{~V}$ and $\mathrm{EC}=20 \mathrm{~g} / \mathrm{l}$ Then MRR is 0.682 $\mathrm{g} / \mathrm{min}[0.490-0.944][\mathrm{P}=100 \%, \mathrm{Q}=20 \%, \mathrm{C}=11.11 \%$, $\mathrm{QTY}=3][\mathrm{T}=131.11]$

Rule 10: If $\mathrm{VL}=16 \mathrm{~V}$ and $\mathrm{FR}=0.6 \mathrm{~mm} / \mathrm{min}$ and $\mathrm{EC}=30$ $\mathrm{g} / \mathrm{l}$ Then MRR is $0.682 \mathrm{~g} / \mathrm{min}[0.490-0.944]$ [ $\mathrm{P}=100 \%$, Q $=6.67 \%, \mathrm{C}=3.70 \%$, QTY $=1][\mathrm{T}=110.37]$

Rule 11: If $\mathrm{VL}=20 \mathrm{~V}$ and $\mathrm{EC}=30 \mathrm{~g} / \mathrm{l}$ Then MRR is 0.682 $\mathrm{g} / \mathrm{min}[0.490-0.944][\mathrm{P}=100 \%, \mathrm{Q}=20 \%, \mathrm{C}=11.11 \%$, $\mathrm{QTY}=3][\mathrm{T}=131.11]$

For SR:
Rule 1: If $\mathrm{VL}=12 \mathrm{~V}$ and $\mathrm{FR}=1.0 \mathrm{~mm} / \mathrm{min}$ Then $\mathrm{SR}$ is $4.305 \mu \mathrm{m}[3.598-4.6][\mathrm{P}=100 \%, \mathrm{Q}=20 \%, \mathrm{C}=11.11 \%$, $\mathrm{QTY}=3][\mathrm{T}=131.11]$

Rule 2: If $\mathrm{VL}=16 \mathrm{~V}$ and $\mathrm{FR}=0.6 \mathrm{~mm} / \mathrm{min}$ Then $\mathrm{SR}$ is $4.305 \mu \mathrm{m}[3.598-4.6][\mathrm{P}=100 \%, \mathrm{Q}=20 \%, \mathrm{C}=11.11 \%$, $\mathrm{QTY}=3][\mathrm{T}=131.11]$

Rule 3: If $\mathrm{VL}=16 \mathrm{~V}$ and $\mathrm{FR}=1.0 \mathrm{~mm} / \mathrm{min}$ Then SR is $4.305 \mu \mathrm{m}[3.598-4.6][\mathrm{P}=100 \%, \mathrm{Q}=20 \%, \mathrm{C}=11.11 \%$, $\mathrm{QTY}=3][\mathrm{T}=131.11]$

Rule 4: If FR $=0.6 \mathrm{~mm} / \mathrm{min}$ and $\mathrm{POR}=5.0 \mathrm{Wt} \%$ Then SR is $4.305 \mu \mathrm{m}[3.598-4.6][\mathrm{P}=100 \%, \mathrm{Q}=20 \%, \mathrm{C}=$ $11.11 \%, \mathrm{QTY}=3][\mathrm{T}=131.11]$ 
Rule 5: If $\mathrm{VL}=12 \mathrm{~V}$ and $\mathrm{FR}=0.2 \mathrm{~mm} / \mathrm{min}$ and $\mathrm{EC}=30$ $\mathrm{g} / \mathrm{l}$ Then $\mathrm{SR}$ is $4.305 \mu \mathrm{m}[3.598-4.6][\mathrm{P}=100 \%, \mathrm{Q}=$ $6.67 \%, \mathrm{C}=3.70 \%, \mathrm{QTY}=1][\mathrm{T}=110.37]$

Rule 6: If $\mathrm{FR}=1.0 \mathrm{~mm} / \mathrm{min}$ and $\mathrm{EC}=30 \mathrm{~g} / \mathrm{l}$ Then $\mathrm{SR}$ is $4.305 \mu \mathrm{m}[3.598-4.6][\mathrm{P}=100 \%, \mathrm{Q}=20 \%, \mathrm{C}=11.11 \%$, QTY=3] [T=131.11]

Rule 7: If $\mathrm{VL}=16 \mathrm{~V}$ and $\mathrm{POR}=2.5 \mathrm{Wt} \%$ Then SR is $4.305 \mu \mathrm{m}[3.598-4.6][\mathrm{P}=100 \%, \mathrm{Q}=20 \%, \mathrm{C}=11.11 \%$, $\mathrm{QTY}=3][\mathrm{T}=131.11]$

Rule 8: If FR $=1.0 \mathrm{~mm} / \mathrm{min}$ and $\mathrm{EC}=20 \mathrm{~g} / \mathrm{l}$ Then SR is $4.305 \mu \mathrm{m}[3.598-4.6][\mathrm{P}=100 \%, \mathrm{Q}=20 \%, \mathrm{C}=11.11 \%$, $\mathrm{QTY}=3][\mathrm{T}=131.11]$

Rule 9: If $\mathrm{VL}=20 \mathrm{~V}$ and $\mathrm{FR}=0.2 \mathrm{~mm} / \mathrm{min}$ Then $\mathrm{SR}$ is $4.943 \mu \mathrm{m}[4.6-5.472][\mathrm{P}=100 \%, \mathrm{Q}=25 \%, \mathrm{C}=11.11 \%$, $\mathrm{QTY}=3][\mathrm{T}=136.11]$

Rule 10: If $\mathrm{VL}=12 \mathrm{~V}$ and $\mathrm{FR}=0.6 \mathrm{~mm} / \mathrm{min}$ and $\mathrm{EC}=10$ $\mathrm{g} / \mathrm{l}$ Then $\mathrm{SR}$ is $4.943 \mu \mathrm{m}[4.6-5.472][\mathrm{P}=100 \%, \mathrm{Q}=$ $8.33 \%, \mathrm{C}=3.70 \%$, QTY $=1][\mathrm{T}=112.03]$

Rule 11: If $\mathrm{VL}=20 \mathrm{~V}$ and $\mathrm{POR}=7.5 \mathrm{Wt} \%$ Then SR is $4.943 \mu \mathrm{m}[4.6-5.472][\mathrm{P}=100 \%, \mathrm{Q}=25 \%, \mathrm{C}=11.11 \%$, $\mathrm{QTY}=3][\mathrm{T}=136.11]$

Rule 12: If FR $=0.2 \mathrm{~mm} / \mathrm{min}$ and $\mathrm{EC}=10 \mathrm{~g} / \mathrm{l}$ Then $\mathrm{SR}$ is $4.943 \mu \mathrm{m}[4.6-5.472][\mathrm{P}=100 \%, \mathrm{Q}=25 \%, \mathrm{C}=11.11 \%$, $\mathrm{QTY}=3][\mathrm{T}=136.11]$

Rule 13: If $F R=0.2 \mathrm{~mm} / \mathrm{min}$ and $\mathrm{EC}=20 \mathrm{~g} / \mathrm{l}$ then $\mathrm{SR}$ is $4.943 \mu \mathrm{m}[4.6-5.472][\mathrm{P}=100 \%, \mathrm{Q}=25 \%, \mathrm{C}=11.11 \%$, $\mathrm{QTY}=3][\mathrm{T}=136.11]$

Rule 14: If $\mathrm{VL}=12 \mathrm{~V}$ and $\mathrm{FR}=0.6 \mathrm{~mm} / \mathrm{min}$ and $\mathrm{EC}=30$ $\mathrm{g} / \mathrm{l}$ then $\mathrm{SR}$ is $4.943 \mu \mathrm{m}$ [4.6-5.472] $[\mathrm{P}=100 \%, \mathrm{Q}=$ $8.33 \%, \mathrm{C}=3.70 \%$, QTY $=1][\mathrm{T}=112.03]$

Rule 15: If $\mathrm{VL}=20 \mathrm{~V}$ and $\mathrm{FR}=0.6 \mathrm{~mm} / \mathrm{min}$ and $\mathrm{EC}=20$ $\mathrm{g} / \mathrm{l}$ then $\mathrm{SR}$ is $4.943 \mu \mathrm{m}$ [4.6-5.472] $[\mathrm{P}=100 \%, \mathrm{Q}=$ $8.33 \%, \mathrm{C}=3.70 \%$, QTY $=1][\mathrm{T}=112.03]$

For ROC:

Rule 1: If $\mathrm{VL}=12 \mathrm{~V}$ and $\mathrm{FR}=0.6 \mathrm{~mm} / \mathrm{min}$ Then $\mathrm{ROC}$ is $0.718 \mathrm{~mm}[0.64-0.90][\mathrm{P}=100 \%, \mathrm{Q}=23.08 \%, \mathrm{C}=$ $11.11 \%$, QTY $=3][\mathrm{T}=134.19]$

Rule 2: If $\mathrm{VL}=12 \mathrm{~V}$ and $\mathrm{FR}=1.0 \mathrm{~mm} / \mathrm{min}$ Then $\mathrm{ROC}$ is $0.718 \mathrm{~mm}[0.64-0.90][\mathrm{P}=100 \%, \mathrm{Q}=23.08 \%, \mathrm{C}=$ $11.11 \%$, QTY $=3][\mathrm{T}=134.19]$

Rule 3: If $\mathrm{VL}=16 \mathrm{~V}$ and $\mathrm{FR}=0.6 \mathrm{~mm} / \mathrm{min}$ and $\mathrm{EC}=20$ $\mathrm{g} / \mathrm{l}$ Then ROC is $0.718 \mathrm{~mm}[0.64-0.90][\mathrm{P}=100 \%, \mathrm{Q}=$ $7.69 \%, \mathrm{C}=3.70 \%$, QTY $=1][\mathrm{T}=111.39]$

Rule 4: If $\mathrm{FR}=0.6 \mathrm{~mm} / \mathrm{min}$ and $\mathrm{EC}=10 \mathrm{~g} / \mathrm{l} \mathrm{Then} \mathrm{ROC}$ is $0.718 \mathrm{~mm}[0.64-0.90][\mathrm{P}=100 \%, \mathrm{Q}=23.08 \%, \mathrm{C}=$ $11.11 \%, \mathrm{QTY}=3][\mathrm{T}=134.19]$

Rule 5: If $\mathrm{FR}=1.0 \mathrm{~mm} / \mathrm{min}$ and $\mathrm{EC}=10 \mathrm{~g} / \mathrm{l} \mathrm{Then} \mathrm{ROC} \mathrm{is}$ $0.718 \mathrm{~mm}[0.64-0.90][\mathrm{P}=100 \%, \mathrm{Q}=23.08 \%, \mathrm{C}=$ $11.11 \%$, QTY $=3$ ] [T = 134.19]

Rule 6: If $\mathrm{VL}=12 \mathrm{~V}$ and POR $=7.5 \mathrm{Wt} \%$ Then ROC is $0.718 \mathrm{~mm}[0.64-0.90][\mathrm{P}=100 \%, \mathrm{Q}=23.08 \%, \mathrm{C}=$ $11.11 \%, \mathrm{QTY}=3]$ [T $=134.19]$

Rule 7: If $\mathrm{VL}=16 \mathrm{~V}$ and $\mathrm{FR}=1.0 \mathrm{~mm} / \mathrm{min}$ and $\mathrm{EC}=20$ $\mathrm{g} / 1$ Then ROC is $0.718 \mathrm{~mm}[0.64-0.90][\mathrm{P}=100 \%, \mathrm{Q}=$ $7.69 \%, \mathrm{C}=3.70 \%$, QTY $=1][\mathrm{T}=111.39]$
Rule 8: If $\mathrm{VL}=16 \mathrm{~V}$ and $\mathrm{POR}=2.5 \mathrm{Wt} \%$ Then $\mathrm{ROC}$ is $0.999 \mathrm{~mm}[0.9-1.16][\mathrm{P}=100 \%, \mathrm{Q}=21.43 \%, \mathrm{C}=$ $11.11 \%$, QTY $=3]$ [T $=132.54]$

Rule 9: If $\mathrm{VL}=20 \mathrm{~V}$ and $\mathrm{EC}=20 \mathrm{~g} / \mathrm{l}$ Then $\mathrm{ROC}$ is 0.999 $\mathrm{mm}[0.9-1.16][\mathrm{P}=100 \%, \mathrm{Q}=21.43 \%, \mathrm{C}=11.11 \%$, QTY $=3][\mathrm{T}=132.54]$

Rule 10: If $\mathrm{VL}=20 \mathrm{~V}$ and POR $=5.0 \mathrm{Wt} \%$ Then $\mathrm{ROC}$ is $0.999 \mathrm{~mm}[0.9-1.16][\mathrm{P}=100 \%, \mathrm{Q}=21.43 \%, \mathrm{C}=$ $11.11 \%, \mathrm{QTY}=3][\mathrm{T}=132.54]$

Rule 11: If FR $=0.2 \mathrm{~mm} / \mathrm{min}$ and $\mathrm{EC}=10 \mathrm{~g} / \mathrm{l}$ Then ROC is $0.999 \mathrm{~mm}[0.9-1.16][\mathrm{P}=100 \%, \mathrm{Q}=21.43 \%, \mathrm{C}=$ $11.11 \%, \mathrm{QTY}=3][\mathrm{T}=132.54]$

Rule 12: If FR $=0.2 \mathrm{~mm} / \mathrm{min}$ and $\mathrm{EC}=20 \mathrm{~g} / \mathrm{l}$ Then ROC is $0.999 \mathrm{~mm}[0.9-1.16][\mathrm{P}=100 \%, \mathrm{Q}=21.43 \%, \mathrm{C}=$ $11.11 \%, \mathrm{QTY}=3][\mathrm{T}=132.54]$

For all the responses:

Rule 1: If $\mathrm{VL}=12 \mathrm{~V}$ and $\mathrm{FR}=0.2 \mathrm{~mm} / \mathrm{min}$ and $\mathrm{EC}=30$ $\mathrm{g} / \mathrm{l}$ and $\mathrm{POR}=7.5 \mathrm{Wt} \%$ Then MRR is $0.346 \mathrm{~g} / \mathrm{min}$ [0.227-0.490] and SR is $4.305 \mu \mathrm{m}$ [3.598-4.6] and ROC is $0.718 \mathrm{~mm}[0.64-0.90][\mathrm{P}=100 \%, \mathrm{Q}=25 \%, \mathrm{C}=3.70 \%$, $\mathrm{QTY}=1][\mathrm{T}=128.70]$

Rule 2: If $F R=0.6 \mathrm{~mm} / \mathrm{min}$ Then MRR is $0.346 \mathrm{~g} / \mathrm{min}$ [0.227-0.490] and SR is $4.305 \mu \mathrm{m}$ [3.598-4.6] and ROC is $0.718 \mathrm{~mm}[0.64-0.90][\mathrm{P}=33.33 \%, \mathrm{Q}=75 \%, \mathrm{C}=$ $11.11 \%$, QTY $=3][\mathrm{T}=119.44]$

Rule 3: If $\mathrm{VL}=16 \mathrm{~V}$ and $\mathrm{FR}=0.2 \mathrm{~mm} / \mathrm{min}$ and $\mathrm{EC}=30$ $\mathrm{g} / \mathrm{l}$ and $\mathrm{POR}=2.5 \mathrm{Wt} \%$ Then MRR is $0.346 \mathrm{~g} / \mathrm{min}$ [0.227-0.490] and SR is $4.305 \mu \mathrm{m}$ [3.598-4.6] and ROC is $0.999 \mathrm{~mm}[0.9-1.16][\mathrm{P}=100 \%, \mathrm{Q}=100 \%, \mathrm{C}=3.70 \%$, $\mathrm{QTY}=1][\mathrm{T}=203.70]$

Rule 4: If $\mathrm{VL}=12 \mathrm{~V}$ and $\mathrm{FR}=0.6 \mathrm{~mm} / \mathrm{min}$ Then MRR is $0.346 \mathrm{~g} / \mathrm{min}$ [0.227-0.490] and $\mathrm{SR}$ is $4.943 \mu \mathrm{m}$ [4.6-5.472] and ROC is $0.718 \mathrm{~mm}$ [0.64-0.90] $[\mathrm{P}=$ $66.67 \%, \mathrm{Q}=100 \%, \mathrm{C}=7.41 \%, \mathrm{QTY}=2][\mathrm{T}=174.08]$ Rule 5: If FR $=0.2 \mathrm{~mm} / \mathrm{min}$ Then MRR is $0.346 \mathrm{~g} / \mathrm{min}$ [0.227-0.490] and SR is $4.943 \mu \mathrm{m}$ [4.6-5.472] and ROC is $0.999 \mathrm{~mm}[0.9-1.16][\mathrm{P}=55.56 \%, \mathrm{Q}=100 \%, \mathrm{C}=$ $18.52 \%, \mathrm{QTY}=5][\mathrm{T}=174.08]$

Rule 6: If FR $=1.0 \mathrm{~mm} / \mathrm{min}$ Then MRR is $0.682 \mathrm{~g} / \mathrm{min}$ [0.490-0.944] and SR is $4.305 \mu \mathrm{m}$ [3.598-4.6] and ROC is $0.718 \mathrm{~mm}[0.64-0.90][\mathrm{P}=55.56 \%, \mathrm{Q}=100 \%, \mathrm{C}=$ $18.52 \%, \mathrm{QTY}=5][\mathrm{T}=174.08]$

Rule 7: If $\mathrm{VL}=20 \mathrm{~V}$ and $\mathrm{FR}=1.0 \mathrm{~mm} / \mathrm{min}$ and $\mathrm{EC}=20$ $\mathrm{g} / \mathrm{l}$ and $\mathrm{POR}=2.5 \mathrm{Wt} \%$ Then MRR is $0.682 \mathrm{~g} / \mathrm{min}$ [0.490-0.944] and SR is $4.305 \mu \mathrm{m}$ [3.598-4.6] and ROC is $0.999 \mathrm{~mm}[0.9-1.16][\mathrm{P}=100 \%, \mathrm{Q}=20 \%, \mathrm{C}=3.70 \%$, $\mathrm{QTY}=1][\mathrm{T}=123.70]$

Rule 8: If $\mathrm{EC}=30 \mathrm{~g} / \mathrm{l}$ Then MRR is $0.682 \mathrm{~g} / \mathrm{min}$ [0.490-0.944] and SR is $4.305 \mu \mathrm{m}$ [3.598-4.6] and ROC is $0.999 \mathrm{~mm}[0.9-1.16][\mathrm{P}=44.44 \%, \mathrm{Q}=80 \%, \mathrm{C}=14.81 \%$, $\mathrm{QTY}=4][\mathrm{T}=139.25]$

Rule 9: If $\mathrm{VL}=20 \mathrm{~V}$ and $\mathrm{EC}=10 \mathrm{~g} / \mathrm{l}$ and $\mathrm{POR}=7.5 \mathrm{Wt} \%$ Then MRR is $0.682 \mathrm{~g} / \mathrm{min}$ [0.490-0.944] and SR is 4.943 $\mu \mathrm{m}$ [4.6-5.472] and ROC is $0.718 \mathrm{~mm}$ [0.64-0.90] [P = $66.67 \%, \mathrm{Q}=100 \%, \mathrm{C}=7.41 \%, \mathrm{QTY}=2][\mathrm{T}=174.08]$ 
Rule 10: If $\mathrm{VL}=20 \mathrm{~V}$ Then MRR is $0.682 \mathrm{~g} / \mathrm{min}$ [0.490-0.944] and SR is $4.943 \mu \mathrm{m}$ [4.6-5.472] and ROC is $0.999 \mathrm{~mm}[0.9-1.16][\mathrm{P}=33.33 \%, \mathrm{Q}=100 \%, \mathrm{C}=$ $11.11 \%$, QTY = 3] [T = 144.44]

Now, for response MRR, rule 7 has the maximum strength of 193.33 which signifies that higher MRR (between 0.490 and $0.944 \mathrm{~g} / \mathrm{min}$ ) can be achieved when the FR during the ECM operation is set at $1.0 \mathrm{~mm} / \mathrm{min}$ (level 3). An increment in FR causes MRR to increase because at higher FR, a tool would move faster towards the workpiece removing more material. An increase in FR would result in decreasing the conducting path between the workpiece and the tool, causing availability of higher current density with rapid anodic dissolution. An overall increase in MRR would also be observed with increase in EC. It can also be observed that approximately $33.33 \%$ of the experiment trials justify fulfilment of this particular rule. Similarly, for response SR, all the rules 9, 11, 12 and 13 have the same maximum strength of 136.11. Based on these rules, it can be propounded that high VL, low FR, low or moderate EC and high POR would cause higher SR of the machined components. On the contrary, it can be concluded that for lower SR (a STB characteristic), low or moderate VL, moderate or high FR, high EC and low or moderate POR are most desirable. Rules 1, 2, 3, 4, 6, 7 and 8, having the same strength of 131.11, support the recommended parametric settings. For this response, FR has the maximum impact, followed by VL and EC. It has been observed by the past researchers that an increase in EC is responsible for better SR due to the anodic smoothening effect at higher current density and removal of reaction products from the machining zone at higher FR. For ROC response, rules 1, 2, 4, 5 and 6 appear to be predominant, all having the same maximum strength of 134.19 . It can be revealed from these rules that for achieving lower ROC, the process engineer must operate the ECM setup at low or moderate VL, moderate or high FR, low EC and high POR. The input parameter VL has the maximum influence on ROC, followed by FR. The ROC would increase with increasing values of VL. At higher VL, the localization effect of current flux flow would decrease causing an increase in the stray current flow in the machining zone, which would be finally responsible for an increase in ROC. The ROC would increase more rapidly at higher voltage zone. In ECM process, removal of material by the stray current would increase with increase in $\mathrm{EC}$ value, resulting in higher ROC. Higher FR would help in quick removal of the sludge from the machined surface, resulting in better ROC.

However, from a practical point of view, it is almost impossible to operate an ECM setup at different parametric combinations for simultaneously attaining the most desired values of all the responses. Looking at the last set of rules, developed combining three responses together, rule 3 (maximum strength of 203.70) states that an ECM parametric mix as $\mathrm{VL}=$ medium, $\mathrm{FR}=$ low, $\mathrm{EC}=$ high and $\mathrm{POR}$
= low tries to achieve the simultaneous fulfilment of all the responses. In this case, lower SR (the most important response from real time machining point of view) is attained, while sacrificing MRR and ROC. However, rule 6 appears to be more interesting to the process engineers as it has the maximum support $(\mathrm{C}=18.52 \%)$, and would achieve the desired response values of higher MRR, lower SR and lower ROC only at high FR.

Based on the same experimental dataset, Rao and Padmanabhan [23] observed that FR was mainly responsible for higher MRR, SR was influenced by EC and VL was accountable for ROC. It was also noticed that for higher MRR, the optimal parametric mix would be VL = High, FR $=$ High, $\mathrm{EC}=$ High and POR $=$ Low. On the other hand, for lower SR and ROC values, the corresponding parametric combinations would be $\mathrm{VL}=$ Moderate, $\mathrm{FR}=$ High, $\mathrm{EC}=$ High and POR = Low, and VL = Low, FR = High, EC = Low and POR $=$ High respectively. It can be interestingly observed that the parametric settings of the considered ECM process as derived based on the association rules closely match with those of Rao and Padmanabhan [23]. As Rao and Padmanabhan [23] did not determine a unique combination of ECM process parameters for satisfying all the responses, the association rule-based parametric combination cannot be compared here.

\subsection{USM process}

In this process, material is primarily removed from the workpiece with the help of high frequency vibrating tool in the presence of abrasive slurry (mixture of fine abrasives with water). Kumar and Khamba [24] used a Sonic-Mill ultrasonic machine (AP-500 model) for making holes in pure titanium (ASTM Grade-I) work material. Type of the tool material, abrasive type, grit size and power rating of the machining setup were considered as the input parameters, while, MRR (in $\mathrm{mm}^{3} / \mathrm{min}$ ), SR (in $\mu \mathrm{m}$ ) and tool wear rate (TWR) (in $\mathrm{mm}^{3} / \mathrm{min}$ ) were the responses. Abrasive type, grit size and power rating had three different operating levels in each, and type of the tool material had five levels, as exhibited in table 8. Based on Taguchi's $L_{18}$ orthogonal array, 18 experiments were conducted and the corresponding response values were measured, as shown in table 9. Among those responses, MRR is of LTB type, and SR and TWR are STB type of quality characteristics.

Following the same procedure as adopted in the first example, the corresponding dependency indexes between the considered USM process attributes are estimated and based on their values, it can be observed that all the attributes are entirely independent of each other and there is no scope of any data deduction. Using $k$-means algorithm and based on the experimental data of table 9, all the three responses are individually grouped into three separate clusters each (low, medium and high), as shown in Figure 2. The details of these clusters are provided in table 10. 
Table 8. USM process parameters and their different levels [24].

\begin{tabular}{|c|c|c|c|c|c|c|c|}
\hline \multirow[b]{2}{*}{$\begin{array}{l}\text { Parameter } \\
\text { Tool material }\end{array}$} & \multirow[b]{2}{*}{$\begin{array}{c}\text { Symbol } \\
\text { TM }\end{array}$} & \multirow[b]{2}{*}{ Unit } & \multicolumn{5}{|c|}{ Level 1} \\
\hline & & & $\begin{array}{c}1 \\
\mathrm{HCS}\end{array}$ & $\begin{array}{c}2 \\
\text { HSS }\end{array}$ & $\begin{array}{c}3 \\
\text { Titanium }\end{array}$ & $\begin{array}{c}4 \\
\text { Ti alloy }\end{array}$ & $\begin{array}{c}5 \\
\text { Cemented carbide }\end{array}$ \\
\hline Abrasive type & AT & & Alumina & $\mathrm{SiC}$ & Boron carbide & & \\
\hline Grit size & GS & Mesh size & 220 & 320 & 500 & & \\
\hline Power rating & PR & W & 100 & 250 & 400 & & \\
\hline
\end{tabular}

Table 9. Experimental plan and responses for the USM process [24].

\begin{tabular}{cccccccc}
\hline Exp. No. & TM & AT & GS & PR & MRR & TWR & SR \\
\hline 1 & 1 & 1 & 1 & 1 & 0.31 & 0.44 & 0.92 \\
2 & 1 & 2 & 2 & 2 & 0.66 & 0.65 & 1.16 \\
3 & 1 & 3 & 3 & 3 & 1.1 & 0.88 & 0.66 \\
4 & 2 & 1 & 1 & 2 & 0.33 & 0.49 & 1.03 \\
5 & 2 & 2 & 2 & 3 & 0.72 & 1.02 & 1.23 \\
6 & 2 & 3 & 3 & 1 & 0.17 & 0.34 & 0.59 \\
7 & 3 & 1 & 2 & 1 & 0.11 & 0.17 & 0.63 \\
8 & 3 & 2 & 3 & 2 & 0.29 & 0.33 & 0.83 \\
9 & 3 & 3 & 1 & 3 & 1.22 & 1.13 & 2.1 \\
10 & 4 & 1 & 3 & 3 & 0.3 & 0.19 & 0.66 \\
11 & 4 & 2 & 1 & 1 & 0.18 & 0.15 & 0.67 \\
12 & 4 & 3 & 2 & 2 & 0.46 & 0.43 & 0.84 \\
13 & 5 & 1 & 2 & 3 & 0.6 & 0.68 & 1.04 \\
14 & 5 & 2 & 3 & 1 & 0.32 & 0.57 & 0.67 \\
15 & 5 & 3 & 1 & 2 & 1.27 & 1.18 & 1.74 \\
16 & 1 & 1 & 3 & 2 & 0.16 & 0.2 & 0.75 \\
17 & 1 & 2 & 1 & 3 & 1.44 & 1.57 & 2.24 \\
18 & 1 & 3 & 2 & 1 & 0.37 & 0.36 & 0.81 \\
\hline
\end{tabular}

Now, the corresponding association rules are developed using ROSE2 software for individual and combined responses.

\section{For MRR:}

Rule 1: If $\mathrm{PR}=100 \mathrm{~W}$ Then MRR is $0.25 \mathrm{~mm}^{3} / \mathrm{min}$ $[0.11-0.45][\mathrm{P}=100 \%, \mathrm{Q}=60 \%, \mathrm{C}=33.33 \%$, QTY $=6]$ $[\mathrm{T}=193.33]$

Rule 2: If AT $=$ Alumina and GS $=500$ mesh size Then MRR is $0.25 \mathrm{~mm}^{3} / \min [0.11-0.45][\mathrm{P}=100 \%, \mathrm{Q}=20 \%$, $\mathrm{C}=11.11 \%$, QTY $=2][\mathrm{T}=131.11]$

Rule 3: If TM $=$ HSS and PR $=250 \mathrm{~W}$ Then MRR is 0.25 $\mathrm{mm}^{3} / \mathrm{min}[0.11-0.45][\mathrm{P}=100 \%, \mathrm{Q}=10 \%, \mathrm{C}=5.56 \%$, $\mathrm{QTY}=1][\mathrm{T}=115.56]$

Rule 4: If $\mathrm{TM}=$ Titanium and $\mathrm{AT}=\mathrm{SiC}$ Then MRR is $0.25 \mathrm{~mm}^{3} / \mathrm{min}[0.11-0.45][\mathrm{P}=100 \%, \mathrm{Q}=10 \%, \mathrm{C}=$ $5.56 \%, \mathrm{QTY}=1][\mathrm{T}=115.56]$

Rule 5: If AT $=\mathrm{SiC}$ and GS $=320$ mesh size Then MRR is $0.61 \mathrm{~mm}^{3} / \mathrm{min}[0.45-1.10][\mathrm{P}=100 \%, \mathrm{Q}=50 \%, \mathrm{C}=$ $11.11 \%, \mathrm{QTY}=2][\mathrm{T}=161.11]$

Rule 6: If $\mathrm{TM}=\mathrm{Ti}$ alloy and GS $=320$ mesh size Then MRR is $0.61 \mathrm{~mm}^{3} / \mathrm{min}[0.45-1.10][\mathrm{P}=100 \%, \mathrm{Q}=25 \%$, $\mathrm{C}=5.56 \%, \mathrm{QTY}=1][\mathrm{T}=130.56]$
Rule 7: If $\mathrm{TM}=$ Cemented carbide and $\mathrm{AT}=$ Alumina Then MRR is $0.61 \mathrm{~mm}^{3} / \mathrm{min}[0.45-1.10][\mathrm{P}=100 \%, \mathrm{Q}=$ $25 \%, \mathrm{C}=5.56 \%$, QTY $=1][\mathrm{T}=130.56]$

Rule 8: If $\mathrm{AT}=$ Boron carbide and GS $=220$ mesh size Then MRR is $1.26 \mathrm{~mm}^{3} / \mathrm{min}[1.10-1.44]$ [P $=100 \%, \mathrm{Q}=$ $50 \%, \mathrm{C}=11.11 \%, \mathrm{QTY}=2][\mathrm{T}=161.11]$

Rule 9: If TM $=$ HCS and PR $=400 \mathrm{~W}$ Then MRR is 1.26 $\mathrm{mm}^{3} / \mathrm{min}[1.10-1.44][\mathrm{P}=100 \%, \mathrm{Q}=50 \%, \mathrm{C}=11.11 \%$, $\mathrm{QTY}=2][\mathrm{T}=161.11]$

For SR:

Rule 1: If $\mathrm{GS}=500$ mesh size Then $\mathrm{SR}$ is $0.71 \mu \mathrm{m}$ $[0.59-0.85][\mathrm{P}=100 \%, \mathrm{Q}=60 \%, \mathrm{C}=33.33 \%$, QTY $=6]$ $[\mathrm{T}=193.33]$

Rule 2: If $\mathrm{AT}=$ Boron carbide and $\mathrm{GS}=320$ mesh size Then SR is $0.71 \mu \mathrm{m}[0.59-0.85][\mathrm{P}=100 \%, \mathrm{Q}=20 \%, \mathrm{C}=$ $11.11 \%$, QTY $=2][\mathrm{T}=131.11]$

Rule 3: If $\mathrm{TM}=$ Titanium and $\mathrm{PR}=100 \mathrm{~W}$ Then SR is $0.71 \mu \mathrm{m}[0.59-0.85][\mathrm{P}=100 \%, \mathrm{Q}=10 \%, \mathrm{C}=5.56 \%$, $\mathrm{QTY}=1][\mathrm{T}=115.56]$

Rule 4: If $\mathrm{TM}=\mathrm{Ti}$ alloy Then $\mathrm{SR}$ is $0.71 \mu \mathrm{m}[0.59-0.85]$ $[\mathrm{P}=100 \%, \mathrm{Q}=30 \%, \mathrm{C}=16.66 \%, \mathrm{QTY}=3][\mathrm{T}=146.66]$ Rule 5: If $\mathrm{AT}=$ Alumina and $\mathrm{GS}=220$ mesh size Then SR is $1.08 \mu \mathrm{m}[0.85-1.50][\mathrm{P}=100 \%, \mathrm{Q}=40 \%, \mathrm{C}=11.11 \%$, $\mathrm{QTY}=2][\mathrm{T}=151.11]$

Rule 6: If $\mathrm{AT}=\mathrm{SiC}$ and GS $=320$ mesh size Then SR is $1.08 \mu \mathrm{m}[0.85-1.50][\mathrm{P}=100 \%, \mathrm{Q}=40 \%, \mathrm{C}=11.11 \%$, $\mathrm{QTY}=2][\mathrm{T}=151.11]$

Rule 7: If $\mathrm{TM}=$ Cemented carbide and $\mathrm{AT}=$ Alumina Then SR is $1.08 \mu \mathrm{m}[0.85-1.50][\mathrm{P}=100 \%, \mathrm{Q}=20 \%, \mathrm{C}=$ $5.56 \%$, QTY $=1][\mathrm{T}=125.56]$

Rule 8: If $\mathrm{AT}=$ Boron carbide and GS $=220$ mesh size Then $\mathrm{SR}$ is $2.03 \mu \mathrm{m}[1.50-2.24][\mathrm{P}=100 \%, \mathrm{Q}=66.67 \%$, $\mathrm{C}=11.11 \%$, QTY $=2][\mathrm{T}=177.78]$

Rule 9: If $\mathrm{TM}=\mathrm{HCS}$ and $\mathrm{AT}=\mathrm{SiC}$ and $\mathrm{GS}=220$ mesh size Then $\mathrm{SR}$ is $2.03 \mu \mathrm{m}[1.50-2.24][\mathrm{P}=100 \%, \mathrm{Q}=$ $33.33 \%, \mathrm{C}=5.56 \%$, QTY $=2][\mathrm{T}=138.89]$

For TWR:

Rule 1: If AT = Alumina and GS $=320$ mesh size Then TWR is $0.25 \mathrm{~mm}^{3} / \mathrm{min}[0.17-0.42][\mathrm{P}=100 \%, \mathrm{Q}=$ $28.57 \%, \mathrm{C}=11.11 \%$, QTY $=2][\mathrm{T}=139.68]$

Rule 2: If $\mathrm{AT}=$ Boron carbide and $\mathrm{PR}=100 \mathrm{~W}$ Then TWR is $0.25 \mathrm{~mm}^{3} / \mathrm{min}[0.17-0.42][\mathrm{P}=100 \%, \mathrm{Q}=$ $28.57 \%, \mathrm{C}=11.11 \%$, QTY $=2][\mathrm{T}=139.68]$

Rule 3: If $\mathrm{TM}=$ Titanium and AT $=$ Alumina Then TWR is $0.25 \mathrm{~mm}^{3} / \mathrm{min}[0.17-0.42][\mathrm{P}=100 \%, \mathrm{Q}=14.29 \%, \mathrm{C}=$ $5.56 \%$, QTY $=1][\mathrm{T}=119.85]$ 
(a)

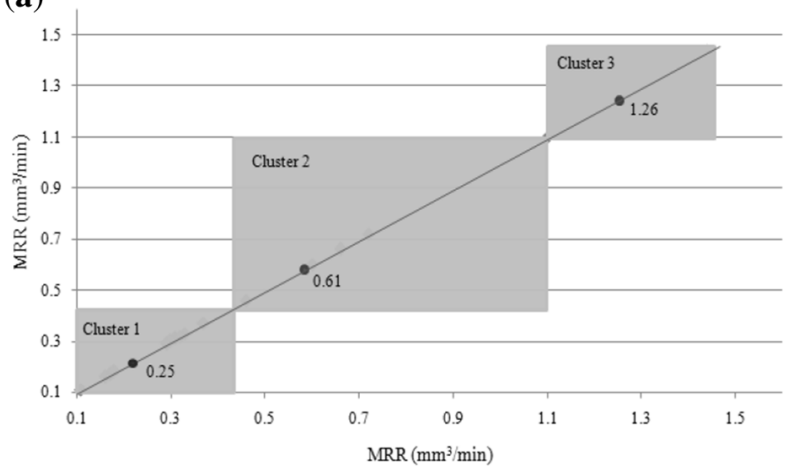

(b)

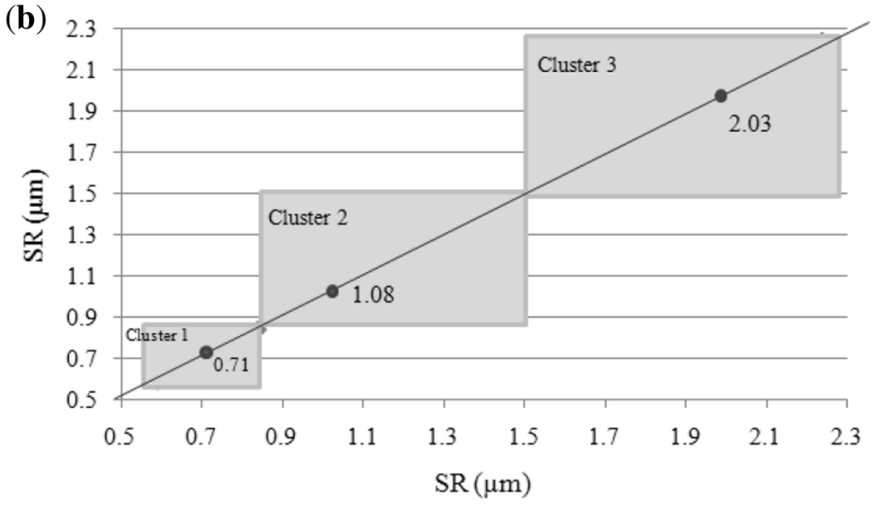

(c)

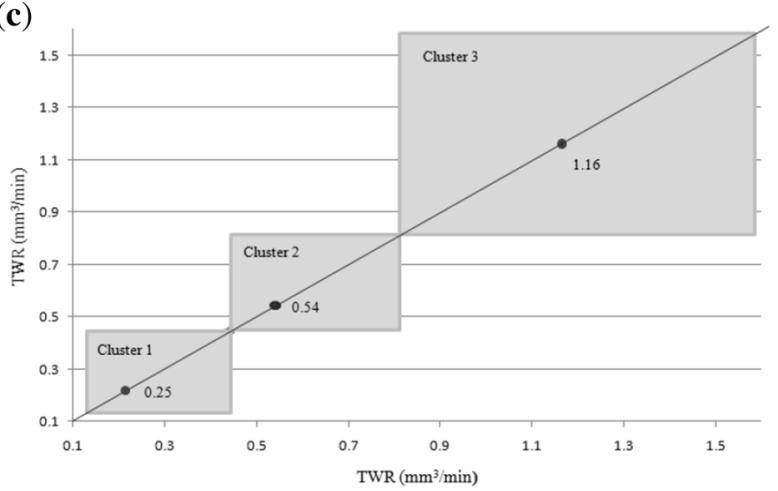

Figure 2. Formation of clusters for the USM responses.

Table 10. Details of the formed clusters for the USM process.

\begin{tabular}{lccccc}
\hline Response & Cluster number & Mean & Range of cluster & Objects & Number of objects in each cluster \\
\hline MRR & Cluster 1 & 0.25 & $0.11-0.45$ & $1,4,6,7,8,10,11,14,16,18$ & 10 \\
& Cluster 2 & 0.61 & $0.45-1.10$ & $2,5,12,13$ & 4 \\
\multirow{3}{*}{ SR } & Cluster 3 & 1.26 & $1.10-1.44$ & $3,9,15,17$ & 4 \\
& Cluster 1 & 0.71 & $0.59-0.85$ & $3,6,7,8,10,11,12,14,16,18$ & 10 \\
\multirow{3}{*}{ TWR } & Cluster 2 & 1.08 & $0.85-1.50$ & $1,2,4,5,13$ & 5 \\
& Cluster 3 & 2.03 & $1.50-2.24$ & $9,15,17$ & 3 \\
& Cluster 1 & 0.25 & $0.17-0.42$ & $6,7,8,10,11,16,18$ & 7 \\
& Cluster 2 & 0.54 & $0.42-0.80$ & $1,2,4,12,13,14$ & 6 \\
\end{tabular}

Rule 4: If $\mathrm{TM}=$ Titanium and $\mathrm{AT}=\mathrm{SiC}$ Then $\mathrm{TWR}$ is $0.25 \mathrm{~mm}^{3} / \mathrm{min}[0.17-0.42][\mathrm{P}=100 \%, \mathrm{Q}=14.29 \%, \mathrm{C}=$ $5.56 \%, \mathrm{QTY}=1]$ [T = 119.85]

Rule 5: If $\mathrm{TM}=\mathrm{Ti}$ alloy and $\mathrm{AT}=\mathrm{SiC}$ Then $\mathrm{TWR}$ is 0.25 $\mathrm{mm}^{3} / \mathrm{min}[0.17-0.42][\mathrm{P}=100 \%, \mathrm{Q}=14.29 \%, \mathrm{C}=5.56 \%$, $\mathrm{QTY}=1]$ [T = 119.85]

Rule 6: If AT = Alumina and GS $=220$ mesh size Then TWR is $0.54 \mathrm{~mm}^{3} / \mathrm{min}[0.42-0.80][\mathrm{P}=100 \%, \mathrm{Q}=$ $33.33 \%, \mathrm{C}=11.11 \%$, QTY $=2$ ] [ $\mathrm{T}=144.44]$

Rule 7: If GS $=320$ mesh size and $\mathrm{PR}=250 \mathrm{~W}$ Then TWR is $0.54 \mathrm{~mm}^{3} / \mathrm{min}[0.42-0.80][\mathrm{P}=100 \%, \mathrm{Q}=$ $33.33 \%, \mathrm{C}=11.11 \%, \mathrm{QTY}=2][\mathrm{T}=144.44]$
Rule 8: If $\mathrm{TM}=$ Cemented carbide and AT $=$ Alumina Then TWR is $0.54 \mathrm{~mm}^{3} / \mathrm{min}[0.42-0.80]$ [P $=100 \%, \mathrm{Q}=$ $16.67 \%, \mathrm{C}=5.56 \%$, QTY $=1]$ [T $=122.23]$

Rule 9: If $\mathrm{TM}=$ Cemented carbide and $\mathrm{AT}=\mathrm{SiC}$ Then TWR is $0.54 \mathrm{~mm}^{3} / \mathrm{min}[0.42-0.80][\mathrm{P}=100 \%, \mathrm{Q}=$ $16.67 \%, \mathrm{C}=5.56 \%$, QTY $=1][\mathrm{T}=122.23]$

Rule 10: If TM $=\mathrm{HCS}$ and $\mathrm{PR}=400 \mathrm{~W}$ Then TWR is 1.16 $\mathrm{mm}^{3} / \mathrm{min}[0.80-1.57][\mathrm{P}=100 \%, \mathrm{Q}=40 \%, \mathrm{C}=11.11 \%$, $\mathrm{QTY}=2]$ [T = 151.11]

Rule 11: If AT $=$ Boron carbide and GS $=220$ mesh size Then TWR is $1.16 \mathrm{~mm}^{3} / \mathrm{min}[0.80-1.57][\mathrm{P}=100 \%, \mathrm{Q}=$ $40 \%, \mathrm{C}=11.11 \%$, QTY $=2]$ [T = 151.11] 
Rule 12: If $\mathrm{TM}=\mathrm{HSS}$ and $\mathrm{AT}=\mathrm{SiC}$ Then TWR is 1.16 $\mathrm{mm}^{3} / \mathrm{min}[0.80-1.57][\mathrm{P}=100 \%, \mathrm{Q}=20 \%, \mathrm{C}=5.56 \%$, $\mathrm{QTY}=1][\mathrm{T}=125.56]$

For all the responses:

Rule 1: If PR $=100 \mathrm{~W}$ Then MRR is $0.25 \mathrm{~mm}^{3} / \mathrm{min}$ [0.11-0.45] and SR is $0.71 \mu \mathrm{m}$ [0.59-0.85] and TWR is $0.25 \mathrm{~mm}^{3} / \mathrm{min}[0.17-0.42][\mathrm{P}=66.67 \%, \mathrm{Q}=57.14 \%, \mathrm{C}=$ $22.22 \%$, QTY $=4][\mathrm{T}=146.03]$

Rule 2: If GS $=500$ mesh size Then MRR is $0.25 \mathrm{~mm}^{3} /$ $\min [0.11-0.45]$ and SR is $0.71 \mu \mathrm{m}[0.59-0.85]$ and TWR is $0.25 \mathrm{~mm}^{3} / \mathrm{min}[0.17-0.42][\mathrm{P}=50 \%, \mathrm{Q}=42.86 \%, \mathrm{C}=$ $16.67 \%$, QTY $=3]$ [T $=109.53]$

Rule 3: If $\mathrm{TM}=$ Cemented carbide and $\mathrm{AT}=\mathrm{SiC}$ and GS $=500$ mesh size and PR $=100 \mathrm{~W}$ Then MRR is $0.25 \mathrm{~mm}^{3} /$ $\min [0.11-0.45]$ and SR is $0.71 \mu \mathrm{m}$ [0.59-0.85] and TWR is $0.54 \mathrm{~mm}^{3} / \mathrm{min}[0.42-0.80][\mathrm{P}=100 \%, \mathrm{Q}=100 \%, \mathrm{C}=$ $5.56 \%$, QTY $=1][\mathrm{T}=205.56]$

Rule 4: If AT = Alumina and GS $=220$ mesh size Then MRR is $0.25 \mathrm{~mm}^{3} / \mathrm{min}$ [0.11-0.45] and SR is $1.08 \mu \mathrm{m}$ [0.85-1.50] and TWR is $0.54 \mathrm{~mm}^{3} / \mathrm{min}[0.42-0.80][\mathrm{P}=$ $100 \%, \mathrm{Q}=100 \%, \mathrm{C}=11.11 \%, \mathrm{QTY}=2][\mathrm{T}=211.11]$

Rule 5: If GS $=320$ mesh size Then MRR is $0.61 \mathrm{~mm}^{3} /$ $\min [0.45-1.10]$ and SR is $1.08 \mu \mathrm{m}[0.85-1.50]$ and TWR is $0.54 \mathrm{~mm}^{3} / \mathrm{min}[0.42-0.80][\mathrm{P}=33.33 \%, \mathrm{Q}=100 \%, \mathrm{C}=$ $11.11 \%, \mathrm{QTY}=2][\mathrm{T}=144.44]$

Rule 6: If $\mathrm{TM}=\mathrm{Ti}$ alloy and $\mathrm{AT}=$ Boron carbide and GS $=320$ mesh size and $\mathrm{PR}=250 \mathrm{~W}$ Then MRR is $0.61 \mathrm{~mm}^{3} /$ $\min [0.45-1.10]$ and SR is $0.71 \mu \mathrm{m}$ [0.59-0.85] and TWR is $0.54 \mathrm{~mm}^{3} / \min [\mathrm{P}=100 \%, \mathrm{Q}=100 \%, \mathrm{C}=5.56 \%$, QTY $=1][\mathrm{T}=205.56]$

Rule 7: If $\mathrm{TM}=\mathrm{HSS}$ and $\mathrm{AT}=\mathrm{SiC}$ and $\mathrm{GS}=320$ mesh size and $\mathrm{PR}=400 \mathrm{~W}$ Then MRR is $0.61 \mathrm{~mm}^{3} / \mathrm{min}$ [0.45-1.10] and SR is $1.08 \mu \mathrm{m}[0.85-1.50]$ and TWR is $1.16 \mathrm{~mm}^{3} / \min [0.80-1.57][\mathrm{P}=100 \%, \mathrm{Q}=100 \%, \mathrm{C}=$ $5.56 \%$, QTY $=1][\mathrm{T}=205.56]$

Rule 8: If GS $=220$ mesh size Then MRR is $1.26 \mathrm{~mm}^{3} /$ $\min$ [1.10-1.44] and SR is $2.03 \mu \mathrm{m}$ [1.50-2.24] and TWR is $1.16 \mathrm{~mm}^{3} / \mathrm{min}[0.80-1.57][\mathrm{P}=50 \%, \mathrm{Q}=100 \%, \mathrm{C}=$ $16.67 \%$, QTY $=3]$ [T $=166.67]$

Rule 9: If TM $=$ HCS and AT $=$ Boron carbide and GS = 500 mesh size and PR $=400 \mathrm{~W}$ Then MRR is $1.26 \mathrm{~mm}^{3} /$ $\min [1.10-1.44]$ and SR is $0.71 \mu \mathrm{m}[0.59-0.85]$ and TWR is $1.16 \mathrm{~mm}^{3} / \mathrm{min}[0.80-1.57][\mathrm{P}=100 \%, \mathrm{Q}=100 \%, \mathrm{C}=$ $5.56 \%$, QTY $=1][\mathrm{T}=205.56]$

For MRR response, rule 1 with the maximum strength of 193.33 states that for low PR, MRR would also be low, and it mostly influences MRR with a high support $(\mathrm{C}=33.33 \%)$. However, rules 8 and 9 are equally important (strength of 161.11) from real time machining standpoint which signify that when AT is boron carbide, GS is low, TM is HCS and $\mathrm{PR}$ is high, the achievable MRR would be high. It has been noticed that in USM process, at higher PR, there is a tremendous increment in the momentum with which the abrasive particles strike with the workpiece surface resulting removal of more material. The HCS as the TM with its moderate to high hardness is responsible for satisfactory MRR due to more indentation in the workpiece when compared with the tool. Similarly, use of boron carbide as the AT results in faster erosion of the workpiece surface, thereby improving MRR. For SR, it can be revealed that GS has the maximum influence on it and high GS (low abrasive particle size) would provide better SR value. Rule 1 for SR justifies this observation with maximum support $(\mathrm{C}=$ $33.33 \%)$ and maximum strength $(\mathrm{T}=193.33)$. Use of a coarser GS would cause an increase in SR, thus deteriorating the surface quality. Coarser abrasive grains would create stronger impacts on the workpiece surface causing generation of larger micro-cavities, which can be associated with poor surface quality. Similarly, in case of TWR, rules 10 and 11 with the same maximum strength of 151.11 state that TM as HCS, AT as boron carbide, low GS and high PR are responsible for higher TWR. However as the lower value of TWR is always preferred, rules 1 and 2 with strength 139.68 seem to be useful to the process engineers. According to these rules, AT as alumina or boron carbide, moderate GS and low PR would lead to lower TWR. The TWR would reduce at finer grit size. On the other hand, higher PR would cause deterioration in TWR due to manifold increase in the momentum of the abrasive grains in this NTM process. When all the three responses are considered together for the generation of association rules, rule 4 with maximum strength of 211.11 supports that AT as alumina and low GS would achieve lower MRR, moderate SR and moderate TWR. However, another rule, i.e. rule 9 also appears to be significant which states that TM as HCS, AT as boron carbide, high GS and high PR lead to higher MRR, lower SR and higher TWR. Although this rule has less strength $(T=205.56)$ than rule 4 , but it identifies the most desirable parametric settings of the considered USM process with higher MRR and lower SR while satisfying the requirements of the present day manufacturing industries.

Based on the experimental data and employing utility concept, Kumar and Khamba [24] identified the individual optimal parametric combinations for maximum MRR: TM $=$ cemented carbide, $\mathrm{AT}=$ boron carbide, $\mathrm{GS}=220$ mesh size and PR $=400 \mathrm{~W}$; and for minimum SR and TWR: TM $=$ titanium alloy, $\mathrm{AT}=$ alumina, $\mathrm{GS}=500$ mesh size and $\mathrm{PR}=100 \mathrm{~W}$. On the other hand, the parametric mix as TM $=$ titanium alloy, $\mathrm{AT}=$ boron carbide, $\mathrm{GS}=500$ mesh size and $\mathrm{PR}=400 \mathrm{~W}$ would simultaneously provide the optimal values of all the responses as MRR $=0.70 \mathrm{~mm}^{3} / \mathrm{min}, \mathrm{SR}=$ $0.77 \mu \mathrm{m}$ and TWR $=0.50 \mathrm{~mm}^{3} / \mathrm{min}$. The association rulebased parametric setting would provide MRR as $1.26 \mathrm{~mm}^{3} /$ min, SR as $0.71 \mu \mathrm{m}$ and TWR as $1.16 \mathrm{~mm}^{3} / \mathrm{min}$.

\subsection{EDM process}

Taking H-11 die steel as the work material, Tripathy and Tripathy [25] conducted 27 Taguchi methodology-based experiments in a powder-mixed EDM setup with 
concentration of the chromium powder in the dielectric medium (commercial grade EDM oil), peak current, pulseon time, duty cycle and gap voltage as the controllable process parameters. On the other hand, MRR (in $\mathrm{mm}^{3} / \mathrm{min}$ ), TWR (in $\mathrm{mm}^{3} / \mathrm{min}$ ), electrode wear ratio (EWR) (in \%) and $\mathrm{SR}$ (in $\mu \mathrm{m}$ ) were the responses. Each of those EDM process parameters was set at three different levels, as exhibited in table 11. Table 12 shows the detailed experimental plan along with the response values. It is worthwhile to mention here that MRR is the only LTB characteristic, and the remaining responses are of STB type.

For this NTM process, the calculated dependency indexes between different attributes ensure that they are totally independent of each other and the original dataset can be directly adopted for subsequent association rules generation. Now, the values of all the four responses are categorized into three clusters each, as depicted in Figure 3. Table 13 provides the details of the generated clusters. Finally, ROSE2 software is adopted for development of the related association rules showing the relationships between the input EDM process parameters and responses.

\section{For MRR:}

Rule 1: If $\mathrm{CCP}=0 \mathrm{~g} / \mathrm{l}$ and $\mathrm{PC}=3 \mathrm{~A}$ Then $\mathrm{MRR}$ is 3.654 $\mathrm{m}^{3} / \mathrm{min}$ [2.564-5.480] $[\mathrm{P}=100 \%, \mathrm{Q}=37.50 \%, \mathrm{C}=$ $11.11 \%, \mathrm{QTY}=3]$ [T = 148.61]

Rule 2: If CCP $=3 \mathrm{~g} / \mathrm{l}$ and PT $=150 \mu \mathrm{s}$ Then MRR is $3.654 \mathrm{~mm}^{3} / \mathrm{min}[2.564-5.480][\mathrm{P}=100 \%, \mathrm{Q}=37.50 \%, \mathrm{C}$ $=11.11 \%$, QTY $=3][\mathrm{T}=148.61]$

Table 11. EDM process parameters and their different operating levels [25].

\begin{tabular}{lllrr}
\hline & & & & \multicolumn{2}{c}{ Level } \\
\cline { 3 - 5 } Parameter & Symbol & Unit & 1 & 2 \\
\hline Concentration of chromium powder & CCP & g/l & 0 & 3 \\
Peak current & PC & A & 3 & 6 \\
Pulse-on time & PT & $\mu$ s & 100 & 70 \\
Duty cycle & DC & $\%$ & 70 & 80 \\
Gap voltage & GV & V & 30 & 40 \\
\hline
\end{tabular}

Table 12. Experimental plan and response values for the EDM process [25].

\begin{tabular}{|c|c|c|c|c|c|c|c|c|c|}
\hline Exp. No. & $\mathrm{CCP}$ & PC & PT & $\mathrm{DC}$ & GV & MRR & TWR & EWR & SR \\
\hline 1 & 0 & 3 & 100 & 70 & 30 & 2.564 & 0.017 & 0.671 & 3.8 \\
\hline 2 & 0 & 3 & 100 & 70 & 40 & 2.649 & 0.019 & 0.735 & 4.1 \\
\hline 3 & 0 & 3 & 100 & 70 & 50 & 2.735 & 0.022 & 0.821 & 4.5 \\
\hline 4 & 0 & 6 & 150 & 80 & 30 & 4.529 & 0.027 & 0.611 & 4.87 \\
\hline 5 & 0 & 6 & 150 & 80 & 40 & 5.47 & 0.03 & 0.561 & 5.45 \\
\hline 6 & 0 & 6 & 150 & 80 & 50 & 6.666 & 0.036 & 0.55 & 5.86 \\
\hline 7 & 0 & 9 & 200 & 90 & 30 & 9.401 & 0.389 & 4.143 & 6.5 \\
\hline 8 & 0 & 9 & 200 & 90 & 40 & 10.256 & 0.486 & 4.747 & 7.47 \\
\hline 9 & 0 & 9 & 200 & 90 & 50 & 10.94 & 0.524 & 4.792 & 9.2 \\
\hline 10 & 3 & 3 & 150 & 90 & 30 & 2.735 & 0.008 & 0.3 & 2.86 \\
\hline 11 & 3 & 3 & 150 & 90 & 40 & 3.076 & 0.009 & 0.318 & 3.14 \\
\hline 12 & 3 & 3 & 150 & 90 & 50 & 5.475 & 0.007 & 0.14 & 3.54 \\
\hline 13 & 3 & 6 & 200 & 70 & 30 & 6.666 & 0.017 & 0.257 & 4.07 \\
\hline 14 & 3 & 6 & 200 & 70 & 40 & 7.222 & 0.01 & 0.146 & 4.56 \\
\hline 15 & 3 & 6 & 200 & 70 & 50 & 7.435 & 0.026 & 0.36 & 4.91 \\
\hline 16 & 3 & 9 & 100 & 80 & 30 & 8.511 & 0.045 & 0.529 & 5.2 \\
\hline 17 & 3 & 9 & 100 & 80 & 40 & 11.829 & 0.057 & 0.489 & 5.63 \\
\hline 18 & 3 & 9 & 100 & 80 & 50 & 15.947 & 0.082 & 0.516 & 5.97 \\
\hline 19 & 6 & 3 & 200 & 80 & 30 & 6.239 & 0.004 & 0.076 & 2.4 \\
\hline 20 & 6 & 3 & 200 & 80 & 40 & 7.435 & 0.003 & 0.046 & 2.84 \\
\hline 21 & 6 & 3 & 200 & 80 & 50 & 8.376 & 0.007 & 0.088 & 2.98 \\
\hline 22 & 6 & 6 & 100 & 90 & 30 & 12.82 & 0.003 & 0.026 & 3.12 \\
\hline 23 & 6 & 6 & 100 & 90 & 40 & 13.076 & 0.007 & 0.054 & 3.36 \\
\hline 24 & 6 & 6 & 100 & 90 & 50 & 14.017 & 0.009 & 0.069 & 3.68 \\
\hline 25 & 6 & 9 & 150 & 70 & 30 & 16.153 & 0.034 & 0.214 & 4.07 \\
\hline 26 & 6 & 9 & 150 & 70 & 40 & 16.692 & 0.042 & 0.256 & 4.68 \\
\hline 27 & 6 & 9 & 150 & 70 & 50 & 17.0684 & 0.049 & 0.289 & 5.04 \\
\hline
\end{tabular}


(a)

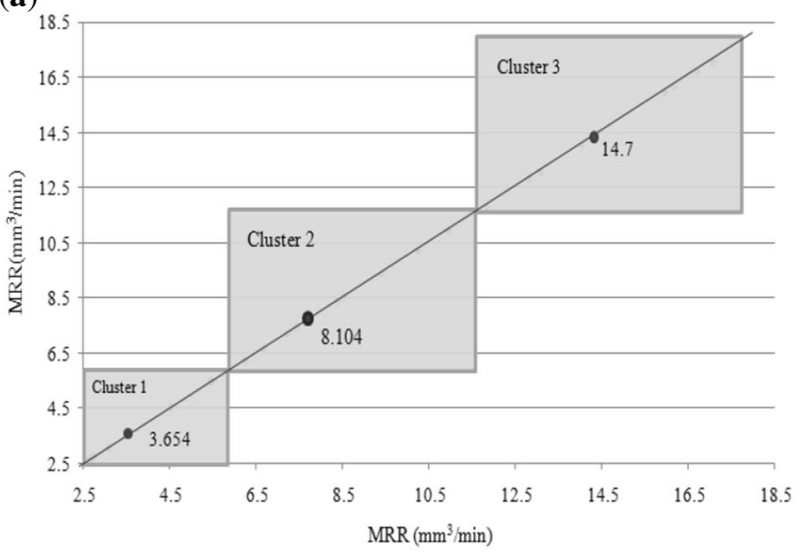

(c)

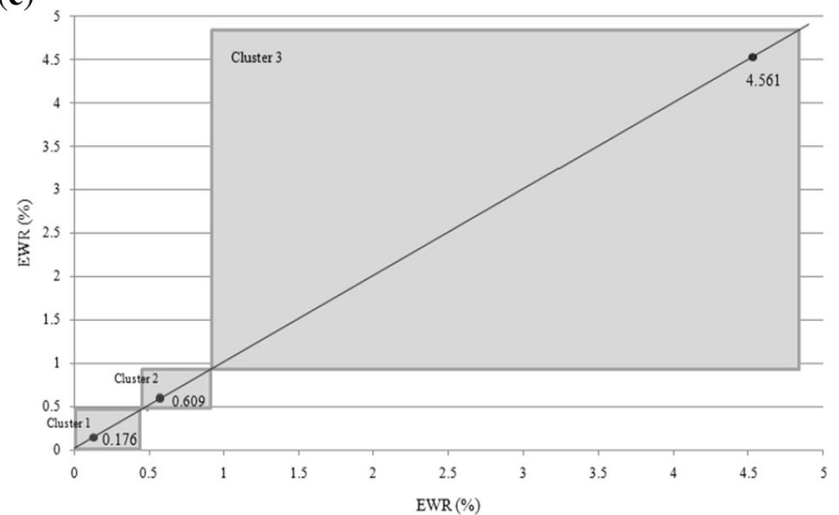

(b)

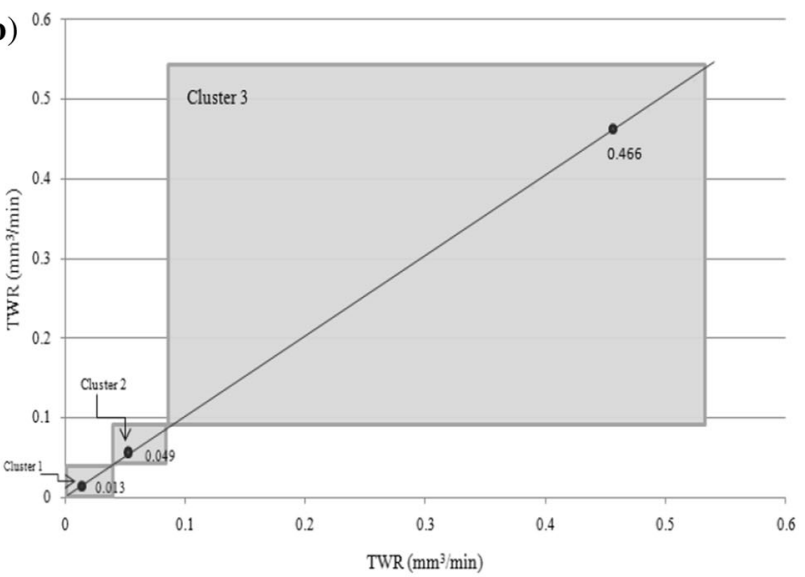

(d)

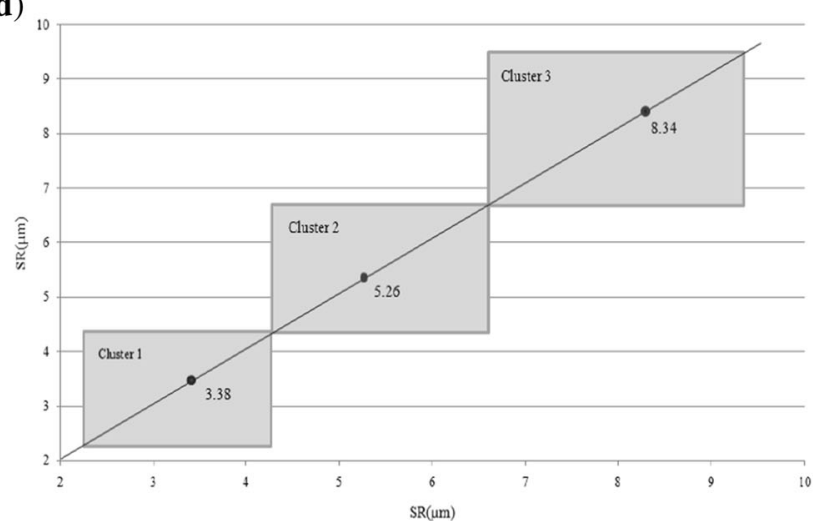

Figure 3. Clusters formed for the EDM responses.

Table 13. Cluster details for the EDM process.

\begin{tabular}{llllll}
\hline Response & Cluster type & Mean & \multicolumn{2}{l}{ Range of cluster } & Object \\
\hline MRR & Cluster 1 & 3.654 & $2.564-5.480$ & $1,2,3,4,5,10,11,12$ & Number of objects in each cluster \\
& Cluster 2 & 8.104 & $5.480-10.96$ & $6,7,8,9,13,14,15,16,19,20,21$ & 8 \\
\multirow{2}{*}{ TWR } & Cluster 3 & 14.7 & $10.96-17.068$ & $17,18,22,23,24,25,26,27$ & 11 \\
& Cluster 1 & 0.013 & $0.003-0.033$ & $1,2,3,4,5,10,11,12,13,14,15,19,20,21,22,23,24$ & 8 \\
& Cluster 2 & 0.049 & $0.033-0.086$ & $6,16,17,18,25,26,27$ & 17 \\
EWR & Cluster 3 & 0.466 & $0.086-0.524$ & $7,8,9$ & 7 \\
& Cluster 1 & 0.176 & $0.026-0.481$ & $10,11,12,13,14,15,19,20,21,22,23,24,25,26,27$ & 3 \\
& Cluster 2 & 0.609 & $0.481-0.830$ & $1,2,3,4,5,6,16,17,18$ & 15 \\
SR & Cluster 3 & 4.561 & $0.830-4.792$ & $7,8,9$ & 9 \\
& Cluster 1 & 3.38 & $2.4-4.2$ & $1,2,10,11,12,13,19,20,21,22,23,24,25$ & 3 \\
& Cluster 2 & 5.26 & $4.2-6.7$ & $3,4,5,6,7,14,15,16,17,18,26,27$ & 13 \\
& Cluster 3 & 8.34 & $6.7-9.2$ & 8,9 & 12 \\
\hline
\end{tabular}

Rule 3: If $\mathrm{PT}=150 \mu \mathrm{s}$ and $\mathrm{DC}=80 \%$ and $\mathrm{GV}=30 \mathrm{~V}$ Then MRR is $3.654 \mathrm{~mm}^{3} / \mathrm{min}[2.564-5.480][\mathrm{P}=100 \%, \mathrm{Q}$ $=12.50 \%, \mathrm{C}=3.70 \%, \mathrm{QTY}=1][\mathrm{T}=116.20]$ Rule 4: If PT $=150 \mu$ s and $\mathrm{DC}=80 \%$ and $\mathrm{GV}=40 \mathrm{~V}$ Then MRR is $3.654 \mathrm{~mm}^{3} / \mathrm{min}[2.564-5.480][\mathrm{P}=100 \%, \mathrm{Q}$ $=12.50 \%, \mathrm{C}=3.70 \%, \mathrm{QTY}=1][\mathrm{T}=116.20]$
Rule 5: If PT $=200 \mu \mathrm{s}$ Then MRR is $8.104 \mathrm{~mm}^{3} / \mathrm{min}$ [5.480-10.96] [P=100\%, Q = 81.82\%, C = 33.33\%, QTY $=9][\mathrm{T}=215.15]$

Rule 6: If $\mathrm{PC}=6 \mathrm{~A}$ and $\mathrm{PT}=150 \mu$ s and $\mathrm{GV}=50 \mathrm{~V}$ Then $\mathrm{MRR}$ is $8.104 \mathrm{~mm}^{3} / \mathrm{min}[5.480-10.96][\mathrm{P}=100 \%, \mathrm{Q}=$ $9.09 \%, \mathrm{C}=3.70 \%$, QTY $=1][\mathrm{T}=112.79]$ 
Rule 7: If PT $=100 \mu$ s and $\mathrm{DC}=80 \%$ and $\mathrm{GV}=30 \mathrm{~V}$ Then MRR is $8.104 \mathrm{~mm}^{3} / \mathrm{min}[5.480-10.96][\mathrm{P}=100 \%$, Q $=9.09 \%, \mathrm{C}=3.70 \%$, QTY $=1][\mathrm{T}=112.79]$

Rule 8: If $\mathrm{CCP}=6 \mathrm{~g} / \mathrm{l}$ and $\mathrm{PC}=9 \mathrm{~A}$ Then MRR is 14.7 $\mathrm{mm}^{3} / \mathrm{min}[10.96-17.068][\mathrm{P}=100 \%, \mathrm{Q}=37.50 \%, \mathrm{C}=$ $11.11 \%$, QTY $=3]$ [T $=148.61]$

Rule 9: If CCP $=6 \mathrm{~g} / \mathrm{l}$ and $\mathrm{PT}=100 \mu$ s Then MRR is 14.7 $\mathrm{mm}^{3} / \min [10.96-17.068][\mathrm{P}=100 \%, \mathrm{Q}=37.50 \%, \mathrm{C}=$ $11.11 \%$, QTY $=3][\mathrm{T}=148.61]$

Rule 10: If PT $=100 \mu$ s and $\mathrm{DC}=80 \%$ and $\mathrm{GV}=40 \mathrm{~V}$ Then MRR is $14.7 \mathrm{~mm}^{3} / \mathrm{min}[10.96-17.068][\mathrm{P}=100 \%$, Q $=12.50 \%, \mathrm{C}=3.70 \%, \mathrm{QTY}=1][\mathrm{T}=116.20]$

Rule 11: If $\mathrm{PT}=100 \mu$ s and $\mathrm{DC}=80 \%$ and $\mathrm{GV}=50 \mathrm{~V}$ Then MRR is $14.7 \mathrm{~mm}^{3} / \mathrm{min}$ [10.96-17.068] [P $=100 \%$, Q $=12.50 \%, \mathrm{C}=3.70 \%, \mathrm{QTY}=1][\mathrm{T}=116.20]$

For TWR:

Rule 1: If $\mathrm{PC}=3 \mathrm{~A}$ Then TWR is $0.013 \mathrm{~mm}^{3} / \mathrm{min}$ [0.003-0.033] $[\mathrm{P}=100 \%, \mathrm{Q}=52.94 \%, \mathrm{C}=33.33 \%$, QTY $=9][\mathrm{T}=186.27]$

Rule 2: If CCP $=3 \mathrm{~g} / \mathrm{l}$ and $\mathrm{PC}=6 \mathrm{~A}$ Then TWR is 0.013 $\mathrm{mm}^{3} / \mathrm{min}[0.003-0.033][\mathrm{P}=100 \%, \mathrm{Q}=17.65 \%, \mathrm{C}=$ $11.11 \%$, QTY $=3]$ [ $\mathrm{T}=128.76]$

Rule 3: If CCP $=6 \mathrm{~g} / \mathrm{l}$ and $\mathrm{PC}=6 \mathrm{~A}$ Then TWR is 0.013 $\mathrm{mm}^{3} / \mathrm{min}[0.003-0.033][\mathrm{P}=100 \%, \mathrm{Q}=17.65 \%, \mathrm{C}=$ $11.11 \%$, QTY $=3][\mathrm{T}=128.76]$

Rule 4: If PT $=150 \mu$ s and $\mathrm{DC}=80 \%$ and $\mathrm{GV}=30 \mathrm{~V}$ Then TWR is $0.013 \mathrm{~mm}^{3} / \mathrm{min}[0.003-0.033][\mathrm{P}=100 \%$, Q $=5.88 \%, \mathrm{C}=3.70 \%$, QTY $=1][\mathrm{T}=109.58]$

Rule 5: If PT $=150 \mu$ s and $\mathrm{DC}=80 \%$ and $\mathrm{GV}=40 \mathrm{~V}$ Then TWR is $0.013 \mathrm{~mm}^{3} / \mathrm{min}[0.003-0.033][\mathrm{P}=100 \%$, Q $=5.88 \%, \mathrm{C}=3.70 \%$, QTY $=1][\mathrm{T}=109.58]$

Rule 6: If CCP $=3 \mathrm{~g} / \mathrm{l}$ and $\mathrm{PC}=9 \mathrm{~A}$ Then TWR is 0.049 $\mathrm{mm}^{3} / \mathrm{min}[0.033-0.086][\mathrm{P}=100 \%, \mathrm{Q}=42.86 \%, \mathrm{C}=$ $11.11 \%, \mathrm{QTY}=3]$ [ $\mathrm{T}=153.97]$

Rule 7: If $\mathrm{CCP}=6 \mathrm{~g} / \mathrm{l}$ and $\mathrm{PT}=150 \mu \mathrm{s}$ Then TWR is $0.049 \mathrm{~mm}^{3} / \mathrm{min}[0.033-0.086][\mathrm{P}=100 \%, \mathrm{Q}=42.86 \%, \mathrm{C}$ $=11.11 \%, \mathrm{QTY}=3][\mathrm{T}=153.97]$

Rule 8: If PT $=150 \mu$ s and $\mathrm{DC}=80 \%$ and $\mathrm{GV}=50 \mathrm{~V}$ Then TWR is $0.049 \mathrm{~mm}^{3} / \mathrm{min}[0.033-0.086][\mathrm{P}=100 \%$, Q $=14.29 \%, \mathrm{C}=3.70 \%$, QTY $=1][\mathrm{T}=117.99]$

Rule 9: If $\mathrm{CCP}=0 \mathrm{~g} / \mathrm{l}$ and $\mathrm{PC}=9 \mathrm{~A}$ Then TWR is 0.466 $\mathrm{mm}^{3} / \mathrm{min}[0.086-0.524][\mathrm{P}=100 \%, \mathrm{Q}=100 \%, \mathrm{C}=$ $11.11 \%, \mathrm{QTY}=3][\mathrm{T}=211.11]$

For EWR:

Rule 1: If CCP $=6 \mathrm{~g} / \mathrm{l}$ Then EWR is $0.176 \%$ [0.026-0.481] $[\mathrm{P}=100 \%, \mathrm{Q}=60 \%, \mathrm{C}=33.33 \%, \mathrm{QTY}=9][\mathrm{T}=193.33]$ Rule 2: If $\mathrm{CCP}=3 \mathrm{~g} / \mathrm{l}$ and $\mathrm{PC}=3 \mathrm{~A}$ Then EWR is $0.176 \%$ [0.026-0.481] $[\mathrm{P}=100 \%, \mathrm{Q}=20 \%, \mathrm{C}=11.11 \%$, QTY $=$ 3] $[\mathrm{T}=131.11]$

Rule 3: If $\mathrm{CCP}=3 \mathrm{~g} / \mathrm{l}$ and $\mathrm{PC}=6 \mathrm{~A}$ Then EWR is $0.176 \%$ $[0.026-0.481][\mathrm{P}=100 \%, \mathrm{Q}=20 \%, \mathrm{C}=11.11 \%$, QTY $=$ 3] $[\mathrm{T}=131.11]$

Rule 4: If $\mathrm{CCP}=0 \mathrm{gm} / 1$ and $\mathrm{PC}=3 \mathrm{~A}$ Then EWR is $0.609 \%[0.481-0.830][\mathrm{P}=100 \%, \mathrm{Q}=33.33 \%, \mathrm{C}=$ $11.11 \%, \mathrm{QTY}=3][\mathrm{T}=144.44]$
Rule 5: If CCP $=0 \mathrm{~g} / \mathrm{l}$ and $\mathrm{DC}=80 \%$ Then EWR is $0.609 \%[0.481-0.830][\mathrm{P}=100 \%, \mathrm{Q}=33.33 \%, \mathrm{C}=$ $11.11 \%, \mathrm{QTY}=3][\mathrm{T}=144.44]$

Rule 6: If $\mathrm{CCP}=3 \mathrm{~g} / \mathrm{l}$ and $\mathrm{PC}=9 \mathrm{~A}$ Then EWR is $0.609 \%$ [0.481-0.830] $[\mathrm{P}=100 \%, \mathrm{Q}=33.33 \%, \mathrm{C}=11.11 \%$, QTY $=3][\mathrm{T}=144.44]$

Rule 7: If $\mathrm{CCP}=0 \mathrm{gm} / 1$ and $\mathrm{PC}=9 \mathrm{~A}$ Then EWR is $4.561 \%[0.830-4.792][\mathrm{P}=100 \%, \mathrm{Q}=33.33 \%, \mathrm{C}=$ $11.11 \%, \mathrm{QTY}=3][\mathrm{T}=144.44]$

For SR:

Rule 1: If $\mathrm{CCP}=3 \mathrm{~g} / \mathrm{l}$ and $\mathrm{PC}=3 \mathrm{~A}$ Then $\mathrm{SR}$ is $3.38 \mu \mathrm{m}$ [2.4-4.2] [P=100\%, Q $=23.08 \%, \mathrm{C}=11.11 \%$, QTY $=3]$ [T $=134.19]$

Rule 2: If $\mathrm{CCP}=6 \mathrm{~g} / \mathrm{l}$ and $\mathrm{PC}=3 \mathrm{~A}$ Then $\mathrm{SR}$ is $3.38 \mu \mathrm{m}$ [2.4-4.2] $[\mathrm{P}=100 \%, \mathrm{Q}=23.08 \%, \mathrm{C}=11.11 \%$, QTY = 3] [T $=134.19]$

Rule 3: If CCP $=6 \mathrm{~g} / \mathrm{l}$ and $\mathrm{PT}=100 \mu \mathrm{s}$ Then SR is 3.38 $\mu \mathrm{m}[2.4-4.2][\mathrm{P}=100 \%, \mathrm{Q}=23.08 \%, \mathrm{C}=11.11 \%$, QTY $=3][\mathrm{T}=134.19]$

Rule 4: If $\mathrm{DC}=70 \%$ and $\mathrm{GV}=30 \mathrm{~V}$ Then SR is $3.38 \mu \mathrm{m}$ [2.4-4.2] $[\mathrm{P}=100 \%, \mathrm{Q}=23.08 \%, \mathrm{C}=11.11 \%, \mathrm{QTY}=3]$ [T $=134.19]$

Rule 5: If PT $=100 \mu$ s and $\mathrm{DC}=70 \%$ and $\mathrm{GV}=40 \mathrm{~V}$ Then SR is $3.38 \mu \mathrm{m}[2.4-4.2][\mathrm{P}=100.00 \%, \mathrm{Q}=7.69 \%, \mathrm{C}$ $=3.70 \%, \mathrm{QTY}=1][\mathrm{T}=111.39]$

Rule 6: If $\mathrm{CCP}=3 \mathrm{~g} / \mathrm{l}$ and $\mathrm{PC}=9 \mathrm{~A}$ Then $\mathrm{SR}$ is $5.26 \mu \mathrm{m}$ [4.2-6.7] [P=100\%, Q $=25 \%, \mathrm{C}=11.11 \%, \mathrm{QTY}=3]$ [T $=136.11]$

Rule 7: If $\mathrm{CCP}=0 \mathrm{~g} / \mathrm{l}$ and $\mathrm{PC}=6 \mathrm{~A}$ Then $\mathrm{SR}$ is $5.26 \mu \mathrm{m}$ [4.2-6.7] $[\mathrm{P}=100 \%, \mathrm{Q}=25 \%, \mathrm{C}=11.11 \%$, QTY $=3][\mathrm{T}$ $=136.11]$

Rule 8: If $\mathrm{DC}=70 \%$ and $\mathrm{GV}=50 \mathrm{~V}$ Then SR is $5.26 \mu \mathrm{m}$ [4.2-6.7] [P $=100 \%, \mathrm{Q}=25 \%, \mathrm{C}=11.11 \%$, QTY $=3][\mathrm{T}$ $=136.11]$

Rule 9: If PT $=200 \mu$ s and $\mathrm{DC}=90 \%$ and $\mathrm{GV}=30 \mathrm{~V}$ Then SR is $5.26 \mu \mathrm{m}[4.2-6.7][\mathrm{P}=100 \%, \mathrm{Q}=8.33 \%, \mathrm{C}=$ $3.70 \%$, QTY $=1]$ [T = 112.03]

Rule 10: If CCP $=3 \mathrm{~g} / \mathrm{l}$ and $\mathrm{DC}=70 \%$ and $\mathrm{GV}=40 \mathrm{~V}$ Then SR is 5.26 $\mu \mathrm{m}[4.2-6.7][\mathrm{P}=100 \%, \mathrm{Q}=8.33 \%, \mathrm{C}=$ $3.70 \%, \mathrm{QTY}=1][\mathrm{T}=112.03]$

Rule 11: If PT $=150 \mu$ s and $\mathrm{DC}=70 \%$ and $\mathrm{GV}=40 \mathrm{~V}$ Then SR is $5.26 \mu \mathrm{m}[4.2-6.7][\mathrm{P}=100 \%, \mathrm{Q}=8.33 \%, \mathrm{C}=$ $3.70 \%, \mathrm{QTY}=1][\mathrm{T}=112.03]$

Rule 12: If PT $=200 \mu$ s and $\mathrm{DC}=90 \%$ and $\mathrm{GV}=40 \mathrm{~V}$ Then SR is $8.34 \mu \mathrm{m}[6.7-9.2][\mathrm{P}=100 \%, \mathrm{Q}=50.0 \%, \mathrm{C}=$ $3.70 \%$, QTY $=1][\mathrm{T}=153.71]$

Rule 13: If PT $=200 \mu$ s and $\mathrm{DC}=90 \%$ and $\mathrm{GV}=50 \mathrm{~V}$ Then $\mathrm{SR}$ is $8.34 \mu \mathrm{m}[6.7-9.2][\mathrm{P}=100 \%, \mathrm{Q}=50.0 \%, \mathrm{C}=$ $3.70 \%$, QTY $=1]$ [T = 153.71]

For all the responses:

Rule 1: If CCP $=0 \mathrm{~g} / \mathrm{l}$ and $\mathrm{PC}=3 \mathrm{~A}$ and $\mathrm{PT}=100 \mu$ s and $\mathrm{DC}=70 \%$ Then MRR is $3.654 \mathrm{~mm}^{3} / \mathrm{min}$ [2.564-5.480] and TWR is $0.013 \mathrm{~mm}^{3} / \mathrm{min}$ [0.003-0.033] and EWR is $0.609 \%$ [0.481-0.830] and SR is $3.38 \mu \mathrm{m}$ [2.4-4.2] [P = $66.67 \%, \mathrm{Q}=100 \%, \mathrm{C}=7.40 \%, \mathrm{QTY}=2][\mathrm{T}=174.07]$ 
Rule 2: If $\mathrm{CCP}=0 \mathrm{~g} / \mathrm{l}$ Then $\mathrm{MRR}$ is $3.654 \mathrm{~mm}^{3} / \mathrm{min}$ [2.564-5.480] and TWR is $0.013 \mathrm{~mm}^{3} / \mathrm{min}$ [0.003-0.033] and EWR is $0.609 \%$ [0.481-0.830] and SR is $5.26 \mu \mathrm{m}$ $[4.2-6.7][\mathrm{P}=33.33 \%, \mathrm{Q}=100 \%, \mathrm{C}=11.11 \%, \mathrm{QTY}=3]$ $[\mathrm{T}=144.44]$

Rule 3: If $\mathrm{CCP}=3 \mathrm{~g} / \mathrm{l}$ and $\mathrm{PC}=3 \mathrm{~A}$ and $\mathrm{PT}=150 \mu$ s and $\mathrm{DC}=90 \%$ Then MRR is $3.654 \mathrm{~mm}^{3} / \min$ [2.564-5.480] and TWR is $0.013 \mathrm{~mm}^{3} / \mathrm{min}$ [0.003-0.033] and EWR is $0.176 \%$ [0.026-0.481] and SR is $3.38 \mu \mathrm{m}$ [2.4-4.2] [P = $100.0 \%, \mathrm{Q}=100 \%, \mathrm{C}=11.11 \%, \mathrm{QTY}=3][\mathrm{T}=211.11]$ Rule 4: If DC $=80 \%$ Then MRR is $8.104 \mathrm{~mm}^{3} / \mathrm{min}$ [5.480-10.96] and TWR is $0.049 \mathrm{~mm}^{3} / \mathrm{min}$ [0.033-0.086] and EWR is $0.609 \%$ [0.481-0.830] and SR is $5.26 \mu \mathrm{m}$ [4.2-6.7] $[\mathrm{P}=22.22 \%, \mathrm{Q}=100 \%, \mathrm{C}=7.42 \%, \mathrm{QTY}=2]$ $[\mathrm{T}=129.62]$

Rule 5: If $\mathrm{CCP}=0 \mathrm{~g} / \mathrm{l}$ and $\mathrm{PC}=9 \mathrm{~A}$ and $\mathrm{PT}=200 \mu$ s and $\mathrm{DC}=90 \%$ and $\mathrm{GV}=30 \mathrm{~V}$ Then MRR is $8.104 \mathrm{~mm}^{3} / \mathrm{min}$ [5.480-10.96] and TWR is $0.466 \mathrm{~mm}^{3} / \mathrm{min}$ [0.086-0.524] and EWR is $4.561 \%$ [0.830-4.792] and SR is $5.26 \mu \mathrm{m}$ [4.2-6.7] [P $=100 \%, \mathrm{Q}=100 \%, \mathrm{C}=3.70 \%$, QTY $=1][\mathrm{T}$ $=203.70]$

Rule 6: If CCP $=0 \mathrm{~g} / \mathrm{l}$ and $\mathrm{PC}=9 \mathrm{~A}$ and $\mathrm{PT}=200 \mu \mathrm{s}$ and $\mathrm{DC}=90 \%$ Then MRR is $8.104 \mathrm{~mm}^{3} / \mathrm{min}$ [5.480-10.96] and TWR is $0.466 \mathrm{~mm}^{3} / \mathrm{min}$ [0.086-0.524] and EWR is $4.561 \%$ [0.830-4.792] and SR is $8.34 \mu \mathrm{m}$ [6.7-9.2] [P= $66.67 \%, \mathrm{Q}=100 \%, \mathrm{C}=7.40 \%, \mathrm{QTY}=2][\mathrm{T}=174.07]$ Rule 7: If $\mathrm{CCP}=3 \mathrm{~g} / \mathrm{l}$ and $\mathrm{PC}=6 \mathrm{~A}$ and $\mathrm{PT}=200 \mu \mathrm{s}$ and $\mathrm{DC}=70 \%$ and $\mathrm{GV}=30 \mathrm{~V}$ Then MRR is $8.104 \mathrm{~mm}^{3} / \mathrm{min}$ [5.480-10.96] and TWR is $0.013 \mathrm{~mm}^{3} / \mathrm{min}$ [0.003-0.033] and EWR is $0.176 \%$ [0.026-0.481] and SR is $3.38 \mu \mathrm{m}$ $[2.4-4.2][\mathrm{P}=100 \%, \mathrm{Q}=25 \%, \mathrm{C}=3.70 \%$, QTY $=1][\mathrm{T}=$ 128.70]

Rule 8: If $\mathrm{CCP}=6 \mathrm{~g} / \mathrm{l}$ and $\mathrm{PC}=3 \mathrm{~A}$ and $\mathrm{PT}=200 \mu \mathrm{s}$ and $\mathrm{DC}=80 \%$ Then MRR is $8.104 \mathrm{~mm}^{3} / \mathrm{min}$ [5.480-10.96] and TWR is $0.013 \mathrm{~mm}^{3} / \mathrm{min}$ [0.003-0.033] and EWR is $0.176 \%$ [0.026-0.481] and SR is $3.38 \mu \mathrm{m}$ [2.4-4.2] [P = $100 \%, \mathrm{Q}=75 \%, \mathrm{C}=11.11 \%, \mathrm{QTY}=3][\mathrm{T}=186.11]$

Rule 9: If $\mathrm{CCP}=3 \mathrm{~g} / \mathrm{l}$ and $\mathrm{PC}=6 \mathrm{~A}$ and $\mathrm{PT}=200 \mu \mathrm{s}$ and $\mathrm{DC}=70 \%$ Then MRR is $8.104 \mathrm{~mm}^{3} / \mathrm{min}$ [5.480-10.96] and TWR is $0.013 \mathrm{~mm}^{3} / \mathrm{min}$ [0.003-0.033] and EWR is $0.176 \%[0.026-0.481]$ and $\mathrm{SR}$ is $5.26 \mu \mathrm{m}$ [4.2-6.7] [P = $66.67 \%, \mathrm{Q}=100 \%, \mathrm{C}=7.40 \%, \mathrm{QTY}=2][\mathrm{T}=174.07]$ Rule 10: If CCP $=3 \mathrm{~g} / \mathrm{l}$ and $\mathrm{PC}=9 \mathrm{~A}$ and $\mathrm{PT}=100 \mu \mathrm{s}$ and $\mathrm{DC}=80 \%$ Then MRR is $14.7 \mathrm{~mm}^{3} / \mathrm{min}$ [10.96-17.068] and TWR is $0.049 \mathrm{~mm}^{3} / \mathrm{min}[0.033-0.086]$ and EWR is $0.609 \%[0.481-0.830]$ and $\mathrm{SR}$ is $5.26 \mu \mathrm{m}$ [4.2-6.7] [P = $66.67 \%, \mathrm{Q}=100 \%, \mathrm{C}=7.40 \%, \mathrm{QTY}=2][\mathrm{T}=174.07]$

Rule 11: If $\mathrm{CCP}=6 \mathrm{~g} / \mathrm{l}$ and $\mathrm{PC}=6 \mathrm{~A}$ and $\mathrm{PT}=100 \mu \mathrm{s}$ and DC $=90 \%$ Then MRR is $14.7 \mathrm{~mm}^{3} / \mathrm{min}$ [10.96-17.068] and TWR is $0.013 \mathrm{~mm}^{3} / \mathrm{min}$ [0.003-0.033] and EWR is $0.176 \%[0.026-0.481]$ and $\mathrm{SR}$ is $3.38 \mu \mathrm{m}$ [2.4-4.2] [P = $100 \%, \mathrm{Q}=100 \%, \mathrm{C}=11.11 \%, \mathrm{QTY}=3][\mathrm{T}=211.11]$ Rule 12: If $\mathrm{CCP}=6 \mathrm{~g} / \mathrm{l}$ and $\mathrm{PC}=9 \mathrm{~A}$ and $\mathrm{PT}=150 \mu \mathrm{s}$ and $\mathrm{DC}=70 \%$ and $\mathrm{GV}=30 \mathrm{~V}$ Then MRR is $14.7 \mathrm{~mm}^{3} / \mathrm{min}$ [10.96-17.068] and TWR is $0.049 \mathrm{~mm}^{3} / \mathrm{min}$
[0.033-0.086] and EWR is $0.176 \%$ [0.026-0.481] and $\mathrm{SR}$ is $3.38 \mu \mathrm{m}[2.4-4.2][\mathrm{P}=100 \%, \mathrm{Q}=100 \%, \mathrm{C}=$ $3.70 \%$, QTY $=1][\mathrm{T}=203.70]$

Rule 13: If $\mathrm{CCP}=6 \mathrm{~g} / \mathrm{l}$ and $\mathrm{PC}=9 \mathrm{~A}$ and $\mathrm{PT}=150 \mu \mathrm{s}$ and DC $=70 \%$ Then MRR is $14.7 \mathrm{~mm}^{3} / \mathrm{min}$ [10.96-17.068] and TWR is $0.049 \mathrm{~mm}^{3} / \mathrm{min}$ [0.033-0.086] and EWR is $0.176 \%[0.026-0.481]$ and $\mathrm{SR}$ is $5.26 \mu \mathrm{m}[4.2-6.7][\mathrm{P}=$ $66.67 \%, \mathrm{Q}=100 \%, \mathrm{C}=7.40 \%, \mathrm{QTY}=2][\mathrm{T}=174.07]$

Amongst the rules generated for MRR, rule 5 having the maximum strength of 215.15 states that high PT leads to moderate value of MRR. Rules 1, 2, 8 and 9 all have the same second maximum strength of 148.61. However rules 1 and 2 lead to lower MRR, while rules 8 and 9 provide higher MRR (most desirable) values. Based on these two rules, $\mathrm{CCP}$ in the dielectric medium emerges out as the most important EDM process parameter, followed by PC and PT for attaining higher values of MRR. High concentration of chromium is responsible for higher MRR. Likewise, high PC and low PT would provide higher MRR. For TWR, rule 9 emerges out as the most important rule with the maximum strength of 211.11 and high support of 11.11 . In this rule, high PC and zero CCP are responsible for higher TWR. Practically, as the lower value of TWR is always preferable, rule 1 with a slightly low strength of 186.27 appears to be interesting to the process engineers. It states that low PC is responsible for achieving lower TWR values. It has been disclosed that when no powder is added to the dielectric and at higher PC, TWR would increase. This is because of the availability of additional thermal energy in the discharge channel. On the other hand, addition of powder particles to the dielectric would cause decrease in its insulating strength and increase the interelectrode gap, resulting in easy removal of debris. For EWR, rule 1 is the most reliable rule with a maximum strength of 193.33. Based on this rule, it can be concluded that for attaining lower EWR, high CCP in the dielectric medium is required. With the addition of powder particles in the dielectric, EWR would decrease because of less tool wear and more material removal from the workpiece. In case of SR response, both the rules 12 and 13 have the maximum strength of 153.71. From these two rules, it can be observed that PT, DC and GV greatly influence SR. High values of PT, DC and GV would cause higher SR which is not at all desired for fulfilling the end requirements. Thus, for lower SR, the values of PT, DC and GV should be kept low. In this process, at higher PC, the quality of the machined surface would deteriorate because large dispersive energy would cause violent sparks and impulsive forces resulting in the formation of larger craters leading to increase in SR. An addition of powder particles in the dielectric fluid would be responsible for achieving lower SR. For the rules developed taking into consideration all the four responses, rules 3 and 11 have the maximum strength of 211.11. In order to attain the desired values of the responses, all the EDM process parameters play significant 
roles. It is always required to have higher value of MRR, and lower values of TWR, EWR and SR. Based on this consideration, rule 11 appears to be the most significant one. It depicts that the parametric combination of $\mathrm{CCP}=6$ $\mathrm{g} / \mathrm{l}, \mathrm{PC}=6 \mathrm{~A}, \mathrm{PT}=100 \mu \mathrm{s}$ and $\mathrm{DC}=90 \%$ would provide higher MRR $\left(\sim 14.7 \mathrm{~mm}^{3} / \mathrm{min}\right)$, lower TWR $\left(\sim 0.013 \mathrm{~mm}^{3} /\right.$ $\min )$, lower EWR $(\sim 0.176 \%)$ and lower SR $(\sim 3.38 \mu \mathrm{m})$. It is quite interesting to notice that for this powder-mixed EDM process, GV has no significant influence on the responses.

Tripathy and Tripathy [25] employed two multi-criteria decision making approaches, i.e. technique for order of preference by similarity to ideal solution (TOPSIS) and grey relational analysis (GRA) for parametric optimization of the said power-mixed EDM process. For TOPSIS method, a parametric combination of CCP $=6 \mathrm{~g} / \mathrm{l}, \mathrm{PC}=6$ $\mathrm{A}, \mathrm{PT}=100 \mu \mathrm{s}, \mathrm{DC}=90 \%$ and $\mathrm{GV}=50 \mathrm{~V}$; and for GRA method, a parametric mix of $\mathrm{CCP}=6 \mathrm{~g} / \mathrm{l}, \mathrm{PC}=3 \mathrm{~A}, \mathrm{PT}=$ $150 \mu \mathrm{s}, \mathrm{DC}=70 \%$ and $\mathrm{GV}=30 \mathrm{~V}$ would simultaneously optimize all the four responses. The results derived based on the association rules exactly corroborate with the parametric combination attained using TOPSIS method which strongly justifies the application potentiality and reliability of the adopted data mining technique in parametric analysis of the considered EDM process.

\section{Conclusions}

In this paper, an attempt is put forward to develop the related association rules to study how each of the considered NTM process outputs is influenced by different input parameters. These rules, presented in the form of simple 'IfThen' statements, can be clearly understood and interpreted by the concerned process engineers. Based on these rules, the best machining conditions for the three NTM processes are obtained as follows:

(a) For the ECM process, only by setting the feed rate at its high level, higher value of MRR, and lower values of SR and ROC can be simultaneously achieved.

(b) For the USM process, tool material as HCS, abrasive type as boron carbide, high grit size and high power rating would help to attain satisfactory values for MRR, SR and TWR.

(c) A high concentration of chromium powder in the dielectric medium, moderate peak current, low pulse-on time and high duty cycle would simultaneously optimize MRR, TWR, EWR and SR in the considered EDM process.

It is observed that the optimal settings of different NTM process parameters derived based on the association rules strongly match with those as identified by the earlier researchers. These rules can also be generated for the other machining processes to study the effects of various input parameters on the responses and determine the most suitable parametric mixes for process optimization.

\section{References}

[1] Jain V K 2010 Advanced Machining Processes. Allied Publishers Pvt. Ltd. New Delhi, India.

[2] [2] Pandey P and Shan H 2017 Modern Machining Processes. Tata McGraw-Hill Publishing Com. Ltd., New Delhi, India

[3] El-Hofy H A-G 2005 Advanced Machining Processes Nontraditional and Hybrid Machining Processes. McGrawHill Education, USA

[4] Kusiak A 2000 Decomposition in data mining: an industrial case study. IEEE Trans. Electron. Packag. Manuf. 23(4): 345-353

[5] Kusiak A, Kern J A, Kernstine K H and Tseng B T L 2000 Autonomous decision-making: a data mining approach. IEEE Trans. Inf. Technol. Biomed. 4(4): 274-284

[6] Wang K 2007 Applying data mining to manufacturing: the nature and implications. J. Intell. Manuf. 18: 487-495

[7] Soni H K, Sharma S and Mishra P K 2016 Association rule mining: a data profiling and prospective approach. Int. J. Curr. Eng. Sci. Res. 3(1): 57-60

[8] Fernandez-Basso C, Ruiz M D and Martin-Bautista M J 2016 Extraction of association rules using big data technologies. Int. J. Des. Nat. Ecodyn. 11(3) 178-185

[9] Prithiviraj P and Porkodi R 2015 A comparative analysis of association rule mining algorithms in data mining: A study. Am. J. Comp. Sci. Eng. Sur. 3(1): 1-10

[10] Sadoyan H, Zakarian A and Mohanty P 2006 Data mining algorithm for manufacturing process control. Int. J. Adv. Manuf. Technol. 28: 342-350

[11] Kusiak A and Kurasek C 2001 Data mining of printed-circuit board defects. IEEE Trans. Robot. Autom. 17(2): 191-196

[12] Kusiak A 2001 Rough set theory: A data mining tool for semiconductor manufacturing. IEEE Trans. Electron. Packag. Manuf. 24(1): 44-50

[13] Chen W-C, Tseng S-S and Wang C-Y 2005 A novel manufacturing defect detection method using association rule mining techniques. Expert Syst. Appl. 29: 807-815

[14] Shahbaz M, Srinivas, Harding J A and Turner M 2006 Product design and manufacturing process improvement using association rules. Proc. Inst. Mech. Eng. B: J. Eng. Manuf. 220: 243-254

[15] Buddhakulsomsiri J, Siradeghyan Y, Zakarian A and Li X 2006 Association rule-generation algorithm for mining automotive warranty data. Int. J. Prod. Res. 44(14): 2749-2770

[16] Haery A, Salmasi N, Yazdi M M and Iranmanesh H 2008 Application of association rule mining in supplier selection criteria. Int. J. Ind. Manuf. Eng. 2(4): 483-487

[17] Jiao J, Zhang L, Zhang Y and Pokharel S 2008 Association rule mining for product and process variety mapping. Int. J. Comp. Integ. Manuf. 21(1): 111-124

[18] Perzyk M, Soroczynski A and Kozlowski J 2010 Applications of rough sets theory in control of foundry processes. Arch. Metall. Mater. 55(3): 889-898 
[19] Ciflikli C and Kahya-Ozyirmidokuz E 2010 Implementing a data mining solution for enhancing carpet manufacturing productivity. Knowl. Based Syst. 23: 783-788

[20] Kamsu-Foguem B, Rigal F and Mauget F 2013 Mining association rules for the quality improvement of the production process. Expert Syst. Appl. 40: 1034-1045

[21] Djatna T and Alitu I M 2015 An application of association rule mining in total productive maintenance strategy: an analysis and modelling in wooden door manufacturing industry. Procedia Manuf. 4: 336-343

[22] Hedau V, Pant P and Sharma K 2016 Material selection using association rule mining. Int. J. Adv. Res. Comp. Sci. 7(3): $230-234$
[23] Rao S R and Padmanabhan G 2014 Optimization of machining parameters in $\mathrm{ECM}$ of $\mathrm{Al} / \mathrm{B}_{4} \mathrm{C}$ composites using Taguchi method. Int. J. Appl. Sci. Eng. 12(2): 87-97

[24] Kumar J and Khamba J S 2010 Multi-response optimisation in ultrasonic machining of titanium using Taguchi's approach and utility concept. Int. J. Manuf. Res. 5(2): 139-160

[25] Tripathy S and Tripathy D K 2016 Multi-attribute optimization of machining process parameters in powder mixed electro-discharge machining using TOPSIS and grey relational analysis. Eng. Sci. Technol. Int. J. 19: 62-70 